Aus der Klinik für Thorax- und Kardiovaskularchirurgie am Herz- und Diabeteszentrum NRW Bad Oeynhausen

- Universitätsklinik- der Ruhr-Universität Bochum Direktor : Prof. Dr. Dr. h. C. R. Körfer

\title{
Predictors of survival in patients requiring IABP support following cardiac surgery
}

\author{
Inaugural-Dissertation \\ zur Erlangung des Doktorgrades der Medizin \\ einer Hohen Medizinischen Fakultät der Ruhr-Universität Bochum
}

\author{
Vorgelegt von \\ Diyar Saeed \\ aus Kerkuk \\ 2007
}


Dekan: Prof. Dr. med. G. Muhr

Referent: Prof. Dr. Dr. h. c. R. Körfer

Korreferent: Prof. Dr. med. A. Laczkovics

Tag der mündlichen Prüfung: 30.10.2007 
Dedication

To my wife Shanaz for her continuous support and encouragement throughout the study 


\section{Table of Contents}

\begin{tabular}{|c|c|}
\hline & Abbreviations \\
\hline 1. & Introduction \\
\hline 1.1 & History of IABP \\
\hline 1.2. & Basic Principles of IABP \\
\hline 1.2 .1 & $\begin{array}{l}\text { Impact of Counterpulsation } \\
\text { on the Arterial Pressure Waveform }\end{array}$ \\
\hline 1.2 .2$. & Timing of IABP \\
\hline 1.2 .3$. & $\begin{array}{l}\text { Effects of IABP on Myocardial Oxygen } \\
\text { Supply and Demand }\end{array}$ \\
\hline 1.2 .4 & $\begin{array}{l}\text { Impact of Balloon Inflation in Diastole } \\
\text { on Coronary Artery Perfusion }\end{array}$ \\
\hline 1.3. & Indications \\
\hline 1.4. & Contraindications \\
\hline 1.5. & $\begin{array}{l}\text { Timing of IABP Insertion with } \\
\text { Regard to the Operation }\end{array}$ \\
\hline 1.6. & IABP Complications \\
\hline 2 . & Material and Methods \\
\hline 2.1 & Definitions \\
\hline 2.2 & Patients \\
\hline 2.3 & Methods \\
\hline 2.4 & Anaesthesia \\
\hline 2.5 & Operation Details \\
\hline 2.6 . & Anticoagulation \\
\hline 2.7 & Insertion Techniques \\
\hline 2.8 & IABP Removal \\
\hline 3. & Statistics \\
\hline 4 . & Results \\
\hline 4.1 & Characteristics of the Patients \\
\hline 4.2 . & $\begin{array}{l}\text { Characteristics of the Study Cohort after } \\
\text { Excluding ECMO Patients }\end{array}$ \\
\hline 5 . & Comment \\
\hline 6 . & Summary \\
\hline 7 . & References \\
\hline & Acknowledgments \\
\hline & Curriculum Vitae \\
\hline
\end{tabular}


Abbreviations

\begin{tabular}{|c|c|}
\hline $\mathrm{AD}$ & Adrenaline \\
\hline ACC time & Aortic Cross Clamp Time \\
\hline $\mathrm{ACT}$ & Activated Clotting Time \\
\hline AK 200 & Renal Dialysis System \\
\hline AVC & Aortic Valve Closure \\
\hline $\mathrm{AVO}$ & Aortic Valve Opening \\
\hline AVR & Aortic Valve Replacement \\
\hline BMI & Body Mass Index \\
\hline BW & Body Weight \\
\hline CABG & Coronary Artery Bypass Graft \\
\hline CAS & Carotid Artery Stenosis \\
\hline $\mathrm{CPB}$ & Cardiopulmonary Bypass \\
\hline CI & Cardiac Index \\
\hline $\mathrm{CK}$ & Creatine Kinase \\
\hline $\mathrm{CPR}$ & Cardiopulmonary Resuscitation \\
\hline CVP & Central Venous Pressure \\
\hline $\mathrm{CVVH}$ & Continuous Veno-Venous Hemofilteration \\
\hline DPTI & Diastolic Pressure Time Index \\
\hline ECC & Extracorporeal Circulation \\
\hline ECG & Electrocardiogram \\
\hline ECMO & Extracorporeal Membrane Oxygenation \\
\hline$E F$ & Ejection Fraction \\
\hline $\operatorname{Exp} \quad(B)$ & Exponent of the B-coefficient \\
\hline $\mathrm{FiO}_{2}$ & Fraction of Inspired Oxygen \\
\hline $\mathrm{HIT}$ & Heparin Induced Thrombocytopenia \\
\hline HLM & Heart-lung Machine \\
\hline HOCM & Hypertrophic Obstructive Cardiomyopathy \\
\hline IAB & Intraaortic Balloon \\
\hline IABP & Intraoartic Balloon Pump \\
\hline
\end{tabular}




\begin{tabular}{|c|c|}
\hline ICU & Intensive Care Unit \\
\hline IQR & Interquartile Range \\
\hline MAP & Mean Arterial Pressure \\
\hline MARS & Molecular Adsorbent Recirculating System \\
\hline mPAP & Mean Pulmonary Artery Pressure \\
\hline MVR & Mitral Valve Replacement \\
\hline LAP & Left Atrial Pressure \\
\hline LBBB & Left Bundle Branch Block \\
\hline $\mathrm{LOS}$ & Low Cardiac Output Syndrome \\
\hline LVAD & Left Ventricular Assist Device \\
\hline LVEDP & Left Ventricular End Diastolic Pressure \\
\hline $\mathrm{OPCAB}$ & Offpump Coronary Artery Bypass \\
\hline PAWP & Pulmonary Artery Wedge Pressure \\
\hline PTCA & Percutaneous Transluminal Angioplasty \\
\hline $\mathrm{PTT}$ & Partial Thromboplastin Time \\
\hline RVAD & Right Ventricular Assist Device \\
\hline SD & Standard Deviation \\
\hline SIRS & Systemic Inflammatory Response Syndrome \\
\hline $\mathrm{SvO}_{2}$ & Mixed Venous Oxygen Saturation \\
\hline SVR & Systemic Vascular Resistance \\
\hline TAH & Total Artificial Heart \\
\hline TTI & Tension Time Index \\
\hline TVR & Tricuspid Valve Replacement \\
\hline $\mathrm{UO}$ & Urine Output \\
\hline VAR & Ventricular Aneurysm Resection \\
\hline $\mathrm{VF}$ & Ventricular Fibrillation \\
\hline VSD & Ventricular Septal Defect \\
\hline
\end{tabular}




\section{Introduction}

Despite continuous expansion of interventional cardiological procedures, cardiac surgery remains the only life-saving treatment in a significant number of patients with heart disease. Continuous development of surgical and anaesthetic procedures yield positive surgical results, enabling elderly patients to have necessary surgeries (Warner et al., 1997). However low cardiac output and cardiogenic shock are serious and life-threatening complications of this surgery (Baskett et al., 2002).

The intra-aortic balloon pump (IABP) is the most commonly used mechanical assist devise in cardiac surgery. The device is used to support patients with low cardiac output. Through an enhancement of stroke volume and favourable diastolic effects, IABP use can increase cardiac output by $20 \%$ (Baskett et al., 2002).

The intra-aortic balloon pump has been widely used in the last 40 years to support a number of patients who exhibit any of the following risk factors for heart failure, such as left main stem disease, low ejection fraction, medical refractory unstable angina, and redo surgery (Christenson et al., 1997; Christenson et al., 1999). IABP has been used also to wean patients from the heart lung machine, or to assist postoperative patients after hemodynamic deterioration. According to previous studies, the incidence of IABP use in cardiac surgery ranges between 1.5-17\% (Torchiana et al., 1997; Vigneswaran et al., 1985).

However despite the use of IABP, mortality remains high in these patients, either because of multiple risk factors present before the operation or due to the occurrence of either intraor postoperative complications. 
In patients receiving IABP intra- or postoperatively, outcomes tend to be worse than in those receiving IABP preoperatively (Baskett et al., 2002). While preoperative IABP support is usually associated with survival rates of more than $74 \%$, intraand postcardiotomy IABP support is associated with an overall survival of only 55\% (range: 27\% to 89\%) (Baskett et al., 2002). It has been demonstrated that $40 \%$ of the patients receiving an intraoperative IABP ultimately require a ventricular assist device (McGee et al., 1980). Some of these patients are bridged to heart transplantation (Korfer et al., 1996; Loebe et al., 1997), while others receive a ventricular assist device (VAD) as destination therapy, and still a significant number of other patients are successfully weaned from VAD (Hausmann et al., 2002; Loebe et al., 1999).

There are several studies which analyze risk factors of those patients with high mortality after IABP Implantation (Aksnes et al., 1996; Corral et al., 1986; Davies et al., 2001; Hausmann et al., 2001; Naunheim et al., 1992), but these studies lack evaluation of the difference in hemodynamic data and cathecholamine doses after IABP implantation with regard to their effect on survival. In one study Ota et al. shows differences in early postoperative cardiac index between CABG and valve operations without measuring other hemodynamic data and cathecholamine requirement with regard to their effect on survival (Ota et al., 1992). Moreover, an IABP score which includes adrenaline requirement, left atrial pressure, urine output, and mixed venous saturation, has recently been developed to predict survival early after IABP implantation in cardiac surgery (Hausmann et al., 2002).

Although the IABP score has been validated at the heart centre where it was developed (Hausmann et al., 2002), the usefulness of this score for other heart centres is unclear at present. 


It was the aim of this investigation (I) to find predictors of
mortality in patients who required IABP intra- or
postoperatively, (II) to develop an IABP score in order to
predict survival early after IABP implantation, and (III) to
assess the early course of hemodynamic parameters and
catecholamine requirement in patients who survived the first 30
days after IABP implantation in comparison with non-survivors.




\subsection{History of IABP}

In 1958, Harken described for the first time a method to treat left ventricular failure by using counterpulsation or diastolic augmentation. He suggested removal of a certain blood volume from the femoral artery during systole and then rapid replacement of this volume during diastole. By increasing coronary perfusion pressure, this concept would augment cardiac output and unload the functioning heart simultaneously (Harken, 1958; Harken, 1976). This method of treatment was limited because of problems with access (need for arteriotomies of both femoral arteries), turbulence and development of massive hemolysis by the pumping apparatus. Even experimental data showed that no augmentation of coronary blood flow was obtained (Dormandy et al., 1969).

Then in the early 1960s Moulopoulus et al. from the Cleveland Clinic developed an experimental prototype of the intra-aortic balloon (IAB) whose inflation and deflation were timed to the cardiac cycle (Moulopoulos et al., 1962; Moulopoulos et al., 1962). In 1968, the initial use in clinical practice of the IABP, and its continued improvement was advanced by Kantrowiz's group (Kahn et al., 1990; Kantrowitz et al., 1968).

In its first years, the IABP required surgical insertion and surgical removal with a balloon size of 15 French. In 1979, after subsequent development in IABP technology, a dramatic headway with the introduction of a percutaneous IAB with a size of 8.5 to 9.5 French was achieved (Bregman, 1980; Hauser et al., 1982). This advance made it possible, even for nonsurgical personnel, to perform an IAB insertion at the patient's bedside. In 1985, the first prefolded IAB was developed.

Today, continued improvements in IABP technology permit safer use, and earlier intervention to provide hemodynamic support. All these progresses have made the IABP a mainstay in the management of ischemic and dysfunctional myocardium. 


\subsection{Basic Principles of IABP}

IABP is instituted by insertion of a distensible polyurethrane, nonthrombogenic balloon (usually $40 \mathrm{cc}$ ) in the descending thoracic aorta. The balloon is passed retrogradely to a position in situ just below the left subclavian artery, but above the renal arteries. The tip of the catheter is visible radiographically as an opaque rectangle, $3 \times 4 \mathrm{~mm}$, paralleling the walls of the descending aorta. An IABP is correctly positioned with this tip in the proximal descending aorta just below the left subclavian artery (Figure 1).

The balloon is mounted on a vascular catheter, which has multiple pores (Figure 2). Helium gas is shuttled from the balloon pump console into the balloon catheter, before escaping through the pores, and finally inflating the balloon. Helium has a low molecular weight, which minimizes shuttle transfer time, and thus increases system efficiency.

Inflation occurs immediately upon onset of diastole. Deflation occurs during isometric contraction or early systole (Figure 1).

Arterial entry is acquired usually through a femoral artery, but axial artery or open chest proximal aortic insertions are alternative options. Femoral insertion is most often accomplished percutaneously, but can be achieved also via an arterial cut down. 


\subsubsection{Impact of Counterpulsation on the Arterial Pressure}

\section{Waveform}

Elevation of intra-aortic pressure during diastole is termed diastolic augmentation. This action is reflected by an increase in diastolic arterial pressure, which becomes the highest pressure point of the arterial waveform. Deflation occurs during isometric contraction, since balloon inflation displaces intra-aortic balloon volume, and aortic end-diastolic pressure is lowered during IAB deflation. Console instrumentation allows the operator to adjust points of inflation-deflation manually within defined safety limits in an effort to maximize hemodynamic benefits to the patient. Although the ECG is used in triggering the pump, it is the arterial pressure waveform that must be used to "time" counterpulsation and assess its benefit on the patient's hemodynamics.

\subsubsection{Timing of IABP}

IABP timing is performed from the ECG or the arterial waveform.

1. ECG: Input to the balloon console is provided from skin leads or the bedside monitor. Inflation is set for the peak of the $\mathrm{T}$ wave at the end of systole with deflation set just before or on the $R$ wave. The use of bipolar pacing eliminates the interpretation of pacing spikes as QRS complexes by the console.

2. Arterial waveform: Inflation should occur at the dicrotic notch with deflation just before the onset of the aortic upstroke. This method is especially useful in the operating room where electrocautery may interfere with the ECG signal. 


\subsubsection{Effects of IABP on Myocardial Oxygen Supply and Demand}

The primary physiological impact of IABP is on myocardial oxygen supply/demand. Oxygen supply is determined by patency of coronary arteries, autoregulation, diastolic perfusion gradient (Aortic diastolic pressure minus left ventricular end diastolic pressure), and the diastolic pressure time index (DPTI). Balloon counterpulsations effect on improving oxygen supply is best appreciated by examining the diastolic pressure time index (DPTI) and tension time index (TTI) (Moccetti et al., 1982; Philips et al., 1975).

The adequacy of the subendocardial perfusion can be predicted by calculating myocardial supply/demand ratio, defined as the ratio of DPTI divided by the systolic pressure TTI. (Figure 3)

Online monitoring of TTI and DPTI (myocardial oxygen supply/demand) ratios is useful as an indicator of adequate left ventricular subendocardial blood flow as impacted by IABP. The subendocardial layer receives most or all of its oxygen supply during diastole (Alcan et al., 1984). As a response to myocardial ischemia, coronary vasodilatation occurs, and subendocardial perfusion becomes pressure dependent (Alcan et al., 1984). Myocardial blood flow is regulated by forces affecting aortic diastolic pressure, left ventricular end diastolic pressure, or diastolic duration. DPTI depends upon the pressure-time relationship of these factors and therefore can be used to estimate diastolic and subendocardial blood flow (Alcan et al., 1984).

Intraaortic balloon inflation increases DPTI and myocardial oxygen delivery. Therefore, IABP provides physiologic assistance to the failing heart by decreasing myocardial oxygen demand or unloading the heart by rapid deflation just before ventricular systole and improving coronary perfusion through rapid inflation, just after aortic valve closure (Lazar et al., 1992; Naunheim et al., 1992). 


\subsubsection{Impact of Balloon Inflation in Diastole on Coronary Artery Perfusion}

Coronary perfusion is potentially increased as the balloon
inflates in diastole (Figure 3). Effective augmentation of
coronary perfusion, however, depends on the degree of
vasodilatation within the coronary bed. Myocardial ischemia is
a potent stimulus for increasing blood flow and oxygen delivery
to the myocardium through vasodilatation. Balloon inflation
displaces blood proximally, potentially increasing coronary
perfusion. IABP thus can potentially improve coronary
perfusion by increasing diastolic pressure and the diastolic
perfusion gradient. Coronary artery flow will increase in
proportion to pressure rise.




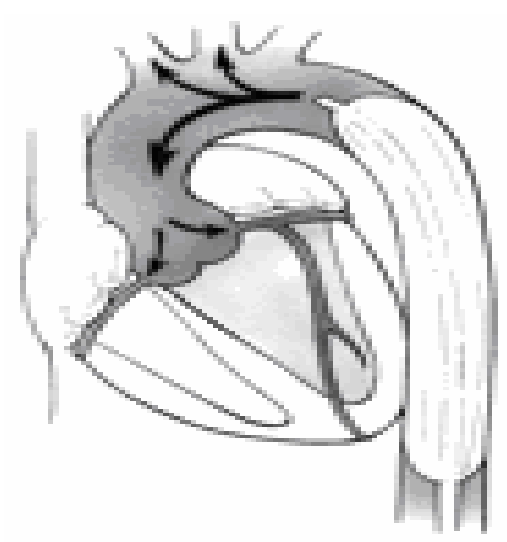

(A) LV Diastole

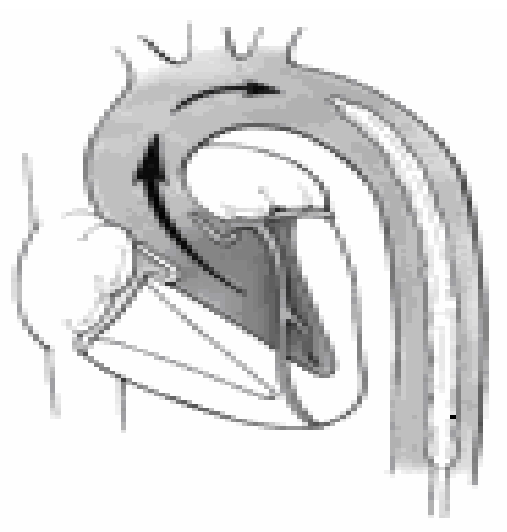

(B) LV Systole

Figure 1: (A) Balloon inflation during left ventricular diastole increases proximal coronary and cerebral perfusion. (B) Balloon deflation during LV systole decreases LV afterload and myocardial oxygen demand.

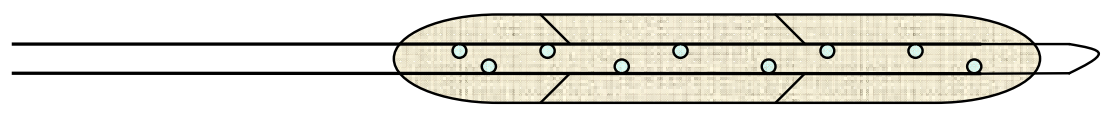

Figure 2: The intraaortic balloon is mounted on a vascular catheter, which contains multiple pores. 


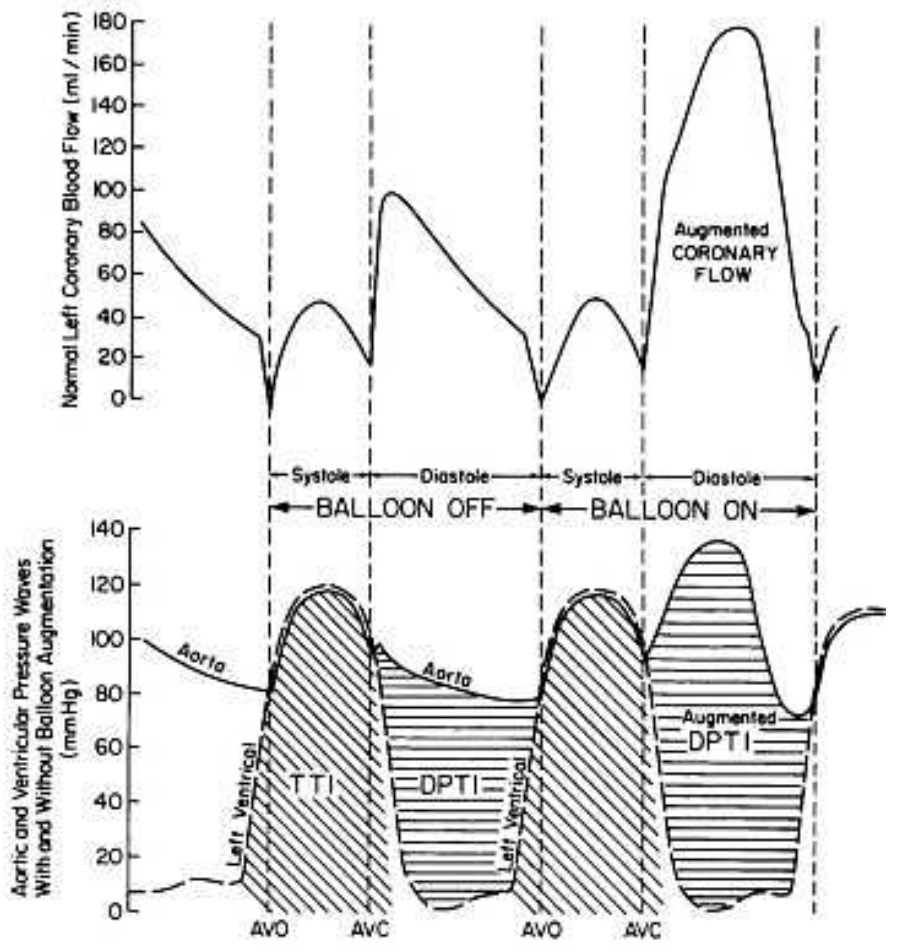

Figure 3: Schematic representation of coronary blood flow, aortic, and left ventricular pressure wave form with / without IABP. (Effects on DPTI and TTI)

a) Inflation of the balloon during diastole (augmentation of the aortic diastolic pressure) increases coronary blood flow (DPTI).

b) Deflation of the balloon occurs just prior to the onset of systole and reduces impedance to left ventricular ejection (TTI) . 


\subsection{Indications}

The currently accepted indications for IABP use have expanded to include (Baskett et al., 2002):

1. Ongoing unstable angina refractory to medical therapy

2. Acute myocardial ischemia/infarction associated with percutaneous transluminal angioplasty (PTCA). The criteria for prophylactic IABP implantation before PTCA include (Kahn JK, 1991):

a. Left ventricular $\mathrm{EF} \leq 30 \%$

b. Angioplasty of the only functional coronary artery

c. Multivessel angioplasty in patients with hypotension

d. Left main coronary artery angioplasty, when the left main artery is unprotected by a patent graft

3. Perioperative low cardiac output syndrome

4. Cardiogenic shock after myocardial infarction

5. Congestive heart failure

6. Bridge to heart transplant

7. Ischemic ventricular septal defect

8. Acute mitral valve insufficiency

9. Poorly controlled perioperative ventricular arrhythmias

Although most physicians accept many of these indications, the decision to use an IABP and the timing of its use are not generally agreed.

\subsection{Contraindications}

The following contraindications of IABP use are well established:

1. Thoracic or abdominal aortic aneurysm

2. Aortic insufficiency

3. Severe pre-existing peripheral vascular disease

4. Lack of definitive therapy for underlying pathology 


\subsection{Timing of IABP Insertion with Regard to the Operation}

The optimal timing of IABP insertion in cardiac surgeries remains controversial and poorly defined (Baskett et al., 2002; Holman et al., 2000). Some of the controversy concerns the definition of a high risk patient. However, much of the benefit derived from preoperative insertion and use of the IABP may be the result of improved myocardial perfusion and stability in the induction of anaesthesia in the early operative period before commencing bypass (Christenson et al., 1997; Gutfinger et al., 1999).

There are some reports which conclude that preoperative IABP insertion in high-risk CABG patients decreased mortality and postoperative length of stay (Christenson et al., 1997; Christenson et al., 1999). High risk was defined as any two of the following: medically refractory unstable angina, ejection fraction $\leq 40 \%$, left main stenosis $\geq 70 \%$, or redo surgery.

In conclusion, there is class I level "A" evidence that preoperative IABP use in ischemic CABG patients is beneficial. There is class I level "B" evidence for preoperative IABP use in CABG patients with ejection fraction $\leq 25 \%$ who are undergoing nonelective operations or reoperation, or who have New York Heart Association class III-IV symptoms (Dietl et al., 1996).

Intraoperative and postoperative IABP insertion is an indication of serious complications, which are often not correctable. Therefore, these patients face a high mortality. Intraoperative balloon use for weaning from cardiopulmonary bypass is well established, although the specific indications are hard to analyze.

An IABP inserted for low cardiac output rather than ischemia is clearly associated with poorer prognosis (Corral et al., 1986; Torchiana et al., 1997).

In Heart and Diabetes Centre North-Rhine-Westfalia, IABP is used preoperatively in the presence of the aforementioned risk 
factors. Meanwhile, it is used intraoperatively to wean patients from the cardiopulmonary machine during medical refractory cardiogenic shock. Postoperatively, the IABP is utilized as the initial mechanical support for patients having low output syndrome (LOS) despite high dosage of inotropics, or after unsuccessful cardiopulmonary resuscitation (>30 minutes), or in patients with recurrent ventricular fibrillation, or prophylactic in patients with postoperative significant ST elevation in ECG. Ultimately, IABP is sometimes used to induce pulsatility in patients with ECMO.

\subsection{IABP Complications}

The following items are reported as complications related to IABP insertion:

1. Inability to inflate balloon: This could occur due to:

- Unipolar atrial pacing (Interpretation of atrial pacing spikes as QRS complex by the console, resulting in ineffective pumping)

- Rapid cardiac rate

- Arrhythmias

- Volume loss from the balloon detected by the console monitor alarms

- Balloon rupture

2. Vascular complications:

- Aortic dissection or rupture of the iliac artery or aorta

- Embolisation to visceral vessels, especially renal arteries

- Distal ischemia

- Paraplegia

3. Thrombocytopenia 
Complications are reported to be primarily associated with the insertion process rather than pumping, removal, or post removal monitoring (Alcan et al., 1983; Kantrowitz et al., 1986). The clinicians technical skills and experience, catheter stiffness, catheter -induced arterial trauma, or combination of thrombotic occlusion and thromboembolism (Alpert et al., 1980) have been implicated as sequelae related to insertion.

The predisposing factors include: gender (more complication in women), age (increased risk with increasing age), pre-existing peripheral vascular disease, duration of IABP therapy, diabetes mellitus, method of insertion (percutaneous insertion associated with lower complication rate as open surgical technique), and finally sheathed insertion of the catheter. Other risk factors are also reported, such as hypertension, smoking, obesity, low cardiac index, and elevated systemic vascular resistance (Cohen et al., 2000; Gottlieb et al., 1984; Kantrowitz et al., 1986; Miller et al., 1992; Tatar et al., 1993) . 


\section{Materials and Methods}

\subsection{Definitions}

Abdominal Operations: This refers to laparotomies, performed due to intestinal ischemia.

AF: This acronym is defined as "atrial fibrillation," diagnosed on basis of preoperative ECG.

CVVH (Continuous Veno-Venous Hemofiltration): This technique is performed using an AK 200 machine for patients with oligoanuria and or patients with high serum creatinine (>8 mg/dl) or blood urea nitrogen (BUN) (>200 mg/dl).

Death after IABP Implantation: This description is used for patients who died in the Heart and Diabetes Centre, NorthRhine-Westfalia and in other hospitals after discharge.

DM: Includes patients with diet, drug controlled, or insulin controlled diabetes mellitus.

Emergency Operation: The term "emergency" refers to an operation which occurs directly after diagnosis either due to instable Angina pectoris or hemodynamic instability or PTCA induced main stem dissection.

Intraoperative IABP: The IABP device is implanted in the operating room, outside the ICU.

LOS: This acronym refers to "low output syndrome" defined as cardiac index $\leq 2.2 \mathrm{~L} / \mathrm{min} / \mathrm{m}^{2}$.

LBBB: ECG findings of prolonged QRS interval $\geq 120 \mathrm{~ms}$, deep $\mathrm{S}$ waves in lead V1, and RsR' waves in lead V6.

MARS (Molecular Adsorbent Recirculating System): This modified dialysis uses an albumin containing dialysate, which is recirculated and perfused online through charcoal and anion exchanger columns. It allows the selective removal of albumin bound substances, and it has been used for patients with high bilirubin values ( $\geq 10 \mathrm{mg} / \mathrm{dl})$.

Paralytic Ileus: Describes nonmechanical obstruction of the bowel due to paralysis of the bowel wall. It is diagnosed on 
the basis of clinical signs with radiological and-or sonographic findings.

Perioperative Myocardial Infarct(PMI): PMI is diagnosed on the basis of perioperative Troponin value of $\geq 15 \mathrm{U} / \mathrm{l}$.

Pneumonia: Pneumonia is diagnosed on the basis of radiological findings of lung infiltrations with clinical signs of infection.

Postoperative Renal Insufficiency: This is defined by either serum creatinine levels $\geq 2 \mathrm{mg} / \mathrm{dl}$ and-or CVVH requirement.

Postoperative Liver Insufficiency: This is defined by either bilirubin values of $\geq 2 \mathrm{mg} / \mathrm{dl}$ and-or MARS requirement.

Preoperative Myocardial Infarct: This diagnosis pertains to patients with Troponin positive acute coronary syndrome with or without ECG change.

Preoperative Renal Insufficiency: This is defined as patients with preoperative creatinine value of $\geq 2 \mathrm{mg} / \mathrm{dl}$ and-or renal dialysis requirement.

Redos: This refers to patients with previous heart operations. Rethoracotomy: This refers to an additional thoracotomy after the initial cardiac operation due to significant bleeding, pericardial tamponade, or hemodynamic instability with requirement of ECMO or VAD.

Septicemia: This is defined by SIRS in addition to the presence of positive blood culture, urine culture, and-or tracheal secrete culture.

Significant Main Stem Stenosis: Main stem stenosis is characterized by $\geq 70 \%$ stenosis, as obtained from coronary angiography .

Significant Carotid Stenosis: This is defined as internal carotid artery stenosis of $\geq 75 \%$, as diagnosed using carotid doppler.

Significant Postoperative ECG Change: It is defined as ST elevation in two or more ECG leads or in the presence of a new left bundle branch block. 
Significant ST Elevation: This refers to new ST elevation in two or more contiguous leads that is $>0.2 \mathrm{mV}$.

SIRS: Systemic Inflammatory Response syndrome is diagnosed by the presence of two or more from the followings:

- Heart rate $>90$ beats per minute

- Body temperature $<36{ }^{\circ} \mathrm{C}\left(96.8{ }^{\circ} \mathrm{F}\right)$ or $>38^{\circ} \mathrm{C}\left(100.4{ }^{\circ} \mathrm{F}\right)$

- Hyperventilation (high respiratory rate) >20 breaths per minute or, on blood gas, a $\mathrm{PaCO}_{2}<32 \mathrm{~mm} \mathrm{Hg}$

- White blood cell count $<4000 \mathrm{cells} / \mathrm{mm}^{3}$ or $>12000 \mathrm{cells} / \mathrm{mm}^{3}$

\subsection{Patients}

A retrospective analysis was performed between January 2002 to January 2004 in the department of thoracic and cardiovascular surgery (Heart Centre North Rhine-Westphalia, Ruhr University of Bochum, Germany) to identify patients who received IABP intra and postoperatively, excluding patients who acquired IABP preoperatively or else following heart transplantation.

We identified 140 patients from a total number of 7872 operations (1.77\%). In four patients (2.85\%), IABP was implanted to generate pulsatility after ECMO implantation, and the hemodynamic data from these patients as well as another 19 patients (13.57\%), who required ECMO, were excluded later from the analysis.

Later, prospective evaluation of the newly developed score system was performed for another 145 patients who required IABP either intra or postoperatively between January 2004 and December 2005 .

\subsection{Methods}

A chart review of the patients from local hospitals' archive was performed to discover relevant clinical information.

Data regarding a number of variables were recorded. Preoperative variables were as follows: patients' weight, BMI, age, sex, diagnosis, surgery type, presence of significant main stem disease and percentage of the stenosis, diabetes mellitus, 
atrial fibrillation, presence of significant carotid stenosis, history of myocardial infarction in the last four weeks, emergency operation, redos, peripheral vascular disease, preoperative renal dialysis requirement, preoperative NYHA class, left ventricular function measured with transthoracic echocardiogram using the planimetric method, and preoperative serum creatinine, measured in $\mathrm{mg} / \mathrm{dl}$.

Intra and postoperative variables recorded include: CPB time, ACC time, implantation indication, implantation place (Intraoperatively or in ICU), rethoracotomy, time between admission and IABP implantation, postoperative ECG change, postoperative venous saturation und urine output in the first and at the sixth hour following implantation, postoperative maximum $\mathrm{CK}, \mathrm{CK}-\mathrm{MB}$, troponin value in $\mathrm{U} / \mathrm{L}$, postoperative maximum creatinine in $\mathrm{mg} / \mathrm{dl}$, bilirubin in $\mathrm{mg} / \mathrm{dl}$, lactate in $\mathrm{mmol} / \mathrm{L}$, duration of support, duration of mechanical ventilation, requirement of CVVH or MARS, ECMO (femoro-femoral or transthoracic) and/or VAD (Ventricular assist device) implantation and the type implanted. Postoperative ileus, abdominal operations, septicemia, pneumonia, IABP complication, neurological findings at discharge, and finally duration of ICU stay and total follow-up time were recorded also.

The above mentioned variables were analyzed using cox regression analysis to identify independent risk factors for mortality.

Afterward, patients who received ECMO after IABP were excluded from the second statistical analysis which included the hemodynamic data and catecholamine requirements. Reasons behind the exclusion stemmed from the performance of most ECMO implantations within one hour after IABP implantation, not to mention the inability to compare hemodynamic data between IABP patients and the ECMO patients. Moreover, it is common practice to reduce the catecholamine doses of patients after ECMO implantation. 
The hemodynamic variables, which had been measured from pulmonary artery and systemic arterial catheters, were recorded at 1 hour, 6 hour, 12 hour, and 24 hour intervals, following IABP implantation. The doses of catecholamines required at different times were recorded as well. The variables available within the first 24 hours after IABP implantation were tested using Cox regression analysis in regard to their effect on 30 day mortality. A new score system could be developed from the results of this analysis.

Lastly, after developing the new score system, we prospectively evaluated it for another 145 patients who received IABP either intra or postoperatively between January 2004 and December 2005 .

At the Heart and Diabetes Centre, North-Rhine-Westfalia, the pulmonary artery catheter is not used routinely. It is only implanted if there are signs of low output syndrome (LOS) such as oliguria, lactate acidosis, cool periphery, low blood pressure, and $\mathrm{SvO}_{2}<60 \%$. Ultimately, there was a small group of patients $(\mathrm{n}=15)$, who lacked a pulmonary catheter even after IABP implantation.

In July 2005, patients were contacted in order to assess longterm survival. In patients who died during the follow-up period, we requested the medical report from the family physicians or from the emergency hospital to determine the date of death. Causes of death were documented as well. 


\subsection{Anaesthesia}

All patients, except emergency cases, received Lormetazepam (13mg dose), Morphine sulphate (7.5-15mg), and Dehydrobenzperidole just one hour before the operation as premedication. Anaesthesia was performed with narcotics, such as Fentanyl (0.1-0.4 mg) and one intravenous anesthetic for example Etomidat or Midazolam, and then the patients were intubated after muscle relaxation. In emergency cases, anaesthesia was carried out with Fentanyl and Midazolam, and only small concentrations of inhalational anaesthetics. After operation, all patients were transferred to the ICU and extubated as soon as possible. Generally, patients that received IABP on basis of resuscitation were extubated relatively late compared with patients who received IABP for other indications. Of course, extubation was performed only in the presence of stable hemodynamics.

\subsection{Operation details}

All procedures were done under mild hypothermia (Blood temperature 27-34 ${ }^{\circ} \mathrm{C}$ ) and hemodilution ( $\mathrm{Hb}$ 7-10 g/dl) with membrane oxygenation. Anticoagulation performed with heparin (400 I.E./kg), and the effect was controlled by measuring ACT (Activated Clotting Time) every 20 minutes.

The operations were performed with non-pulsatile perfusion, except in patients with significant internal carotid artery stenosis ( $\geq 75 \%$ stenosis), in which pulsatile perfusion was used.

The extracorporeal circulation (ECC) flow rate ranged between $\left(2.2-2.6 \mathrm{~L} / \mathrm{min} / \mathrm{m}^{2}\right)$ and the mean perfusion pressure ranged between 40-90 mm Hg. The ECC was performed on pH-stat-basis.

Perioperative antibiotic prophylaxis was performed with Cephazolin (2 gm) prior to skin incision, and it was given for merely one day after CABG operations, for one week following 
valve operations, and up to six weeks in patients with endocarditis.

\subsection{Anticoagulation}

Anticoagulation in patients with IABP was started postoperatively with heparin in absence of significant thoracic bleeding (i.e. when the amount of bleeding $\leq 50 \mathrm{ml} / \mathrm{hr}$ ). Heparin effect was monitored using PTT with target PTT of 1.5-2 times control. In patients with HIT (Heparin Induced Thrombocytopenia), thrombininhibitors such as, Lepirudin (Refludan) or more recently Argatroban, were used.

\subsection{Insertion techniques}

A. Percutaneous insertion: Percutaneous insertion is performed by the seldinger technique, placing the balloon through a sheath and over a guidewire. Generally, the sheath can be left in place or removed from the artery. Only "sheathless" systems were used in the Heart and Diabetes Centre, North-RhineWestfalia, to minimize occlusion of the femoral vessels, and the balloon is placed just distal to the left subclavian artery. Use of small (8 French), sheathless catheters, and percutaneous insertion is associated with less complications (Elahi et al., 2005).

B. Surgical insertion: This is accomplished through exposure of the femoral artery and placement of the balloon through a sidearm graft or directly into the vessel, through an arteriotomy or a percutaneous sheath. The transthoracic balloon is inserted via the ascending aorta and the patients are transferred to the ICU with open chest until hemodynamic stabilization (usually after 2-4 days). Then, IABP is removed surgically, and the chest is closed. 
In the majority (94.3\%) of patients, IABP was inserted via the femoral artery using the seldinger technique. Transthoracic implantation was performed in four patients (2.85\%), and open surgical implantation was performed in only four patients (2.85\%) as well.

Two types of commercially available IABP systems were used Datascope (97E, 98XT, and CS100) (Datascope Corporation, Oakland, New Jersy, USA) and Arrow (Auto CAT 2 WAVE and ACAT 1 PLUS) (Arrow Deutchland, Erding, Germany). It is noteworthy that the majority of implanted IABP were from the Datascope company •

\subsection{IABP removal}

A percutaneous IABP was removed without exposing the femoral puncture site. The balloon catheter was disconnected from the pump and completely deflated using a 50-mL syringe. Using steady pressure over the femoral puncture site, the balloon catheter was withdrawn smoothly, and pressure was maintained over the puncture site for 30 minutes using a special compression device (Pilote). Then, pressure was reduced until reaching a pressure lower than systolic blood pressure. If the balloon was inserted via a cut-down, the balloon was removed in the operating room. The puncture site was closed with sutures. If blood flow to the lower limb was impaired after removal, a local thromboembolectomy using Fogarty catheters and an angioplasty procedure using a vein patch is performed. 


\section{Statistics}

Data was analyzed using SPSS software (SPSS for Windows version 11.0, SPSS Inc.; Chicago, IL). Normal distribution of the data was tested using Kolmogorov-Smirnov test. Normal distribution was considered with $p$ value above 0.05 . Cox regression test was applied for univariate analysis of the parameters with regard to their effect on survival. Those parameters demonstrating a marginal significance of $\mathrm{p}<0.1$ were included in multivariate stepwise analysis (Cox regression test) to detect independent predictors of survival. A $p$ value of $\leq 0.05$ was considered to be significant. Survival rates were calculated with the Kaplan-Meier product-limit estimator.

In order to assess differences in the hemodynamic data and catecholamine doses between survivors and non survivors, patients who required ECMO after IABP were excluded. The unpaired student $t$ test for normally distributed data and Man Whitney test for not-normally distributed data were used to compare these variables in regard to their effect on 30 day mortality. Time effect within the study groups were evaluated using the Friedman test. For the purpose of finding earlier predictors of survival, the association of statistically significant factors, which were available within the first 24 hours after IABP implantation with 30 day mortality, were tested again in a univariate Cox regression model. Every univariate variable showing marginal significance $(P \leq 0.1)$ was then tested in a Cox multivariate model and removed stepwise if no significant influence was discovered. A p-value $\leq 0.05$ was considered statistically significant. Based on coefficients of the multivariate analysis, an IABP score formula was determined. All patients were scored using this formula. Data are expressed as mean with standard deviation or median with interquartile range. 


\section{Results}

\subsection{Characteristics of the patients:}

Between January 2002 to January 2004, 140 patients, from a total of 7872 operations at the Heart Centre, Bad Oeynhausen, received IABP intra or postoperatively (1.77\%). Seventy eight patients (55.71\%) could be successfully weaned and discharged, while 62 patients (44.28\%) died in our ICU. Early mortality (30 days) was 45.7\%, median ICU duration was 7 days (IQR: 4-17 days), and mean follow-up time was 337.63 days ( \pm 405.54 SD). One year mortality rate was $55.71 \%(n=78)$, while two year mortality rate reached $58.57 \%(n=82)$.

Patient age ranged between $37-90$ years (mean $69.19 \pm 9.4$ SD), 75 patients (53.6\%) were $\geq 70$ years old. There were 72 males (51.42\%) and 68 females (48.57\%), with body weight ranging from 43-109 kg (mean 74.14 $\pm 3.36 \mathrm{SD}$ ), and BMI ranging between $17.22-39.54 \mathrm{~kg} / \mathrm{m}^{2} \quad$ (mean $\left.26 \pm 3.6 \quad \mathrm{SD}\right) . \quad$ Preoperative measurements recorded EF ranging between 17-87\% (mean $53.31 \pm$ $16 \mathrm{SD}), 25$ patients (17.85\%) had $\mathrm{EF} \leq 35 \%$ before the operation; 50 patients (35.71\%) had diabetes mellitus preoperative; 31 patients (22.14\%) had atrial fibrillation; 25 patients (17.85\%) had significant main stem stenosis $\geq 70 \% ; 40$ patients (28.57\%) were redos. In 21 patients (15\%), the operations were performed on emergency basis, and 27 patients (19.28\%) experienced myocardial infarction in the last 4 weeks before operation.

NYHA preoperative classification was as following: class I, 4 patients (2.85\%); class II, 18 patients (12.85\%); class III, 89 patients (63.57\%); class IV, 29 patients (20.71\%). Median preoperative creatinine was $1.1 \mathrm{mg} / \mathrm{dl}$ ( $\mathrm{IQR}=0.9-1.4 \mathrm{mg} / \mathrm{dl}$ ), while 11 patients (7.85\%) had preoperative creatinine value $\geq 2$ mg/dl. Five patients (3.57\%) were on renal dialysis before the operation. Thirty-five patients (25\%) had preoperative peripheral vascular disease. Thirty-one patients (22.14\%) had relevant carotid stenosis. One operation was conducted without 
cardiopulmonary bypass (OPCAB). The rest of the operations were performed with cardiopulmonary bypass. Cardiopulmonary bypass ( $\mathrm{CPB}$ ) time ranged between 14-357 minutes (mean= $113.46 \pm$ $55.15 \mathrm{SD})$. Aortic cross clamp time ranged between 0-145 minutes (mean $44.81 \pm 30.58$ SD). The cardiac operations performed are listed in Table 1. Other operations were as follows: one De Vega plastic + subtotal pericardiotomy, one myectomy by HOCM + mitral valve annuloplasty + VSD closure, one ascending aortic replacement, and lastly one patient with ventricle rupture closure following previous CABG operation. In 47 patients (33.57\%), IABP was implanted intraoperatively; in 93 patients (66.42\%) IABP implantation was performed in the ICU. Rethoracotomy was performed in 42 patients (30\%) due to cardiac tamponade or bleeding.

Implantation indications are shown in Table 2. In 43 patients (30.71\%), IABP was implanted during CPR either because of recurrent $\mathrm{VF}$ or asystole. Median duration of mechanical ventilation was 4 days (IQR: 1-13 days). Median time between ICU admission and IABP implantation was 4.5 hours (IQR: 1-11 hours). In one patient, IABP was implanted on postoperative day 14 during resuscitation after PTCA trial, IABP median duration of support was 4 days (IQR: 2-6 days). In one patient, it was difficult to wean from IABP, which is why she received an IABP three times. (Her age prevented VAD implantation.) She died due to electromechanical dissociation after 43 days.

In total, 23 (16.42\%) patients had the combination of IABP with ECMO, among them 19 patients (13.57\%) received ECMO after IABP, while only four patients (2.85\%) received IABP after ECMO. VAD implantation was performed in a total of nine patients $(6.42$ \%). Four patients (2.85\%) received Cardiowest $\mathrm{TAH}$, and another four patients (2.85\%) received Thoratec (LVAD or BVAD), while one patient (0.71\%) obtained the combination of LVAD (Abiomed) 
with RVAD (centrifugal pump). In seven patients (5\%), VAD were implanted following previous ECMO support. Whereas in two patients (1.42\%), VAD were implanted following IABP implantation without earlier ECMO support, one patient (0.7\%) received Cardiowest $\mathrm{TAH}$ and the other patient (0.7\%) received Thoratec (TAH). Median time between IABP and ECMO or VAD implantation was 1.2 hours (IQR: $1-3$ hours).

Early postoperative ECG changes were as follows: 59 patients (42.14\%) showed no change, 44 patients (31.42\%) had significant ST-elevation, 18 patients (12.85\%) had new LBBB, in 19 patients (13.57\%) the interpretation was impossible due to AV pacing. Median postoperative maximal CK was $1580 \mathrm{U} / \mathrm{L}$ (IQR: 692-3149.5 $\mathrm{U} / \mathrm{L}$ ), median postoperative maximal CK/MB was $77 \mathrm{U} / \mathrm{L}$ (IQR: $30.5-$ $227.5 \mathrm{U} / \mathrm{L})$, median postoperative maximal cardial troponin was $47.8 \mathrm{U} / \mathrm{L}$ (IQR: 18.36-103 U/L), and median postoperative maximal lactate was $6.2 \mathrm{mmol} / \mathrm{L}$ (IQR:3.75-10.1 mmol/L). Perioperative myocardial infarction with a troponin value of $\geq 15 \mathrm{U} / \mathrm{L}$ was detected in $79.28 \%$ of the patients.

Median postoperative maximal creatinine was $2.1 \mathrm{mg} / \mathrm{dl}$ (IQR: $1.5-3.2 \mathrm{mg} / \mathrm{dl})$; therefore, $71.42 \%$ developed postoperative renal insufficiency and $57.14 \%$ required CVVH. Meanwhile, MARS therapy was performed in $10.71 \%$ of the patients due to severe liver insufficiency. Exactly 26.42\% developed postoperative paralytic ileus, and $12.14 \%$ required laparatomy for intestinal ischemia. In one patient $(0.71 \%)$, laparotomy was performed due to lower gastrointestinal tract bleeding. Septicemia was diagnosed in $42.14 \%$ (25\% with IABP, $17.14 \%$ after IABP explanation). Pneumonia was diagnosed in 15\% of the patients, during the follow up in the ICU. 
Table 1: Type of Operations Performed

\begin{tabular}{|ccc|}
\hline Type of Operation & Total Number Performed & Percentage \\
\hline CABG* & 74 & 52.85 \\
AVR & 15 & 10.71 \\
MVR & 6 & 4.28 \\
CABG+AVR & 20 & 14.28 \\
CABG+MVR & 12 & 8.57 \\
CABG+AVR+MVR & 1 & 0.71 \\
CABG+VAR & 2 & 1.42 \\
AVR+MVR & 3 & 2.14 \\
TVR & 2 & 1.42 \\
TVR+MVR & 1 & 0.71 \\
Others & 4 & 2.85 \\
Total & 140 & 100 \\
\hline
\end{tabular}

* CABG: Coronary Artery Bypass Graft, AVR: Aortic Valve Replacement, MVR: Mitral Valve Replacement, TVR: Tricuspid Valve Replacement, VAR: Ventricular Aneurysm Resection

Table 2: Implantation Indications

\begin{tabular}{|ccc|}
\hline Implantation indication & $\begin{array}{c}\text { Total } \\
\text { Number }\end{array}$ & Percentage \\
\hline LOS* & 44 & 31.42 \\
During CPR & 43 & 30.71 \\
Failure to wean from HLM & 39 & 27.85 \\
Prophylactic due to ST Elevation & 7 & 5.0 \\
Recurrent VF & 3 & 2.14 \\
\hline
\end{tabular}

* LOS: LOW Output Syndrome, CPR: Cardiopulmonary Resuscitation, HLM: Heart Lung Machine, VF: Ventricular Fibrillation, ECMO: Extracorporeal Membrane Oxygenation 
By the time of discharge, there were 82 patients (58.57\%) without neurological abnormality. Twenty one patients (15\%) had hemiparesis or were in coma before death or discharge, while 37 patients (26.42\%) were on narcotics just before death (Neurological examination could not be performed).

The aforementioned variables were tested in regard to their effect on mortality, and statistically significant prognostic indicators for univariate analysis are shown in Tables 3 and 4. After including variables with $p$ value $<0.1$ in the multivariate analysis, maximal CK-MB, maximal lactate in the first 24 hours, postoperative ischemia induced paralytic ileus, postoperative renal insufficiency, and implantation after cardiac operations other than CABG and valve operations were the most important predictors of survival. Table 5 shows these variables.

Regarding causes of death, 23 patients (28\%) died due to multiple organ failure (MOF); 38 patients $(46.4 \%$ ) died due to cardiogenic shock; 17 patients (20.8\%) had septicemia; two patients (2.4\%) died due to a central cause (following perioperative cerebral ischemia); and finally two patients $(2.4 \%)$ died due to other causes.

In this study, 5\% IABP related complication rate was recorded, which is comparable to other studies with different IABP related complications rates (2.9 - 47\%) (Arafa et al., 1999; Collier et al., 1986; Elahi et al., 2005; Kuki et al., 2001; Scholz et al., 1998). IABP technical failure occurred in three patients (2.14\%) and was managed by changing the pump without any negative influence on the outcome; thus, it is not regarded as IABP related complication. One patient died due to IABP related limb ischemia complicated by septicemia. 
Table 3: Statistically Significant Prognostic Indicators in Univariate Analysis (Categorical Variables)

\begin{tabular}{|c|c|c|c|c|c|}
\hline Variable & $\begin{array}{c}\text { o Survivors } \\
(\text { No. }=58)\end{array}$ & $\begin{array}{c}\text { Non survivors } \\
(\text { No. }=82)\end{array}$ & $\begin{array}{l}E x p \\
(B)\end{array}$ & $\begin{array}{c}95 \% C I \text { for } \\
\operatorname{Exp} \text { (B) }\end{array}$ & $\begin{array}{c}P \\
\text { Value* }\end{array}$ \\
\hline Female Sex & 33.3 & 59 & 1.900 & $1.223-2.952$ & 0.004 \\
\hline Age $\geq 70$ Years & 40.4 & 62.7 & 1.817 & $1.164-2.838$ & 0.009 \\
\hline Weight $\leq 75 \mathrm{Kg}$ & 42.1 & 60.2 & 1.666 & $1.072-2.591$ & 0.023 \\
\hline CAS $\star \star$ & 15.8 & 26.6 & 1.513 & $0.917-2.496$ & 0.1 \\
\hline Rethoracotomy & 15.8 & 40.7 & 2.021 & $1.290-3.166$ & 0.002 \\
\hline Implantation in ICU & 57.9 & 72.3 & 1.551 & $0.959-2.511$ & 0.07 \\
\hline Perioperative Infarct & 68.4 & 86.8 & 2.295 & $1.178-4.471$ & 0.015 \\
\hline $\begin{array}{l}\text { Implantation by Operations } \\
\text { other than CABG and Valve }\end{array}$ & 0 & 4.8 & 2.786 & $1.012-7.673$ & 0.047 \\
\hline PO Renal Insufficiency & 45.6 & 90.8 & 6.235 & $2.849-13.643$ & $<0.001$ \\
\hline PO Liver Insufficiency & 42.1 & 65.8 & 1.72 & $1.067-2.773$ & 0.026 \\
\hline MARS Therapy & 3.5 & 15.6 & 1.869 & $1.001-3.49$ & 0.05 \\
\hline Paralytic Ileus & 8.9 & 40.3 & 3.058 & $1.897-4.93$ & $<0.001$ \\
\hline Laparatomy & 5.3 & 16.9 & 2.154 & $1.173-3.955$ & 0.013 \\
\hline ECMO Implantation & 3.5 & 25.3 & 2.491 & $1.505-4.123$ & $<0.001$ \\
\hline Septicemia & 22.8 & 56.6 & 1.402 & $1.074-1.831$ & 0.013 \\
\hline Implantation during $\mathrm{CPR}$ & 19.3 & 38.6 & 1.989 & $1.276-3.102$ & 0.002 \\
\hline
\end{tabular}

* Cox regression analysis, ** $\operatorname{Exp}(B)=$ exponent of the $B$-coefficient, $C I=$ confidence interval, CAS : Internal Carotid Artery Stenosis, ICU : Intensive Care Unit, CABG : Coronary Artery Bypass Graft, PO: Postoperative, MARS : Molecular Adsorbent Recirculating System, ECMO : Extracorporeal Membrane Oxygenation, CPR : Cardiopulmonary Resuscitation 
Table 4: Statistically Significant Prognostic Indicators in Univariate Analysis (Continuous Variables)

\begin{tabular}{|c|c|c|c|c|c|}
\hline Variable & Survivors & $\begin{array}{l}\text { Non } \\
\text { survivors }\end{array}$ & $\begin{array}{r}\operatorname{Exp} \\
(B)\end{array}$ & $\begin{array}{c}\text { 95 } C I \\
\text { for } \\
\operatorname{Exp}(B)\end{array}$ & $\begin{array}{c}P \\
\text { Value* }\end{array}$ \\
\hline Height in $\mathrm{cm}$ & $\begin{array}{c}170.6 \\
( \pm 8.8 \mathrm{SD})\end{array}$ & $\begin{array}{c}166.5 \\
( \pm 9.8 \mathrm{SD})\end{array}$ & 0.968 & $\begin{array}{l}0.946- \\
0.990\end{array}$ & 0.005 \\
\hline Max. CK-MB level in U/L & $\begin{array}{c}47 \\
(I Q R: 20.5- \\
90.5)\end{array}$ & $\begin{array}{c}111.5 \\
(\mathrm{IQR}: 48- \\
262.2)\end{array}$ & 1.001 & $\begin{array}{l}1.001- \\
1.002\end{array}$ & $<0.001$ \\
\hline Max. Troponin level in U/L & $\begin{array}{c}33.3 \\
(\mathrm{IQR}: 12.6- \\
69)\end{array}$ & $\begin{array}{c}62.5 \\
(\mathrm{IQR}: 27.8- \\
36.5)\end{array}$ & 1.004 & $\begin{array}{l}1.002- \\
1.005\end{array}$ & $<0.001$ \\
\hline $\begin{array}{c}\text { Max. Lactate in First } 24 \text { Hour } \\
\text { Postoperative in mmol/L }\end{array}$ & $\begin{array}{c}5.1 \\
(\mathrm{IQR}: 3.2- \\
7)\end{array}$ & $\begin{array}{c}7.7 \\
(\mathrm{IQR}: 4- \\
12.5)\end{array}$ & 1.094 & $\begin{array}{l}1.060- \\
1.130\end{array}$ & $<0.001$ \\
\hline
\end{tabular}

${ }^{*}$ Cox regression analysis

Table 5: Results of Multivariate Analysis

\begin{tabular}{|c|c|c|c|}
\hline \multirow[b]{2}{*}{ Variable } & \multicolumn{3}{|c|}{$95 \%$ CI } \\
\hline & $\operatorname{Exp}(B)$ & for $\operatorname{Exp}(B)$ & $P$ value \\
\hline Max. CK-MB level & 1.001 & $1.000-1.002$ & 0.004 \\
\hline Max. lactate in First 24 Hour & 1.055 & $1.019-1.092$ & 0.003 \\
\hline Paralytic Ileus & 2.389 & $1.418-4.026$ & 0.001 \\
\hline Postoperative Renal Insufficiency & 4.312 & $1.917-9.699$ & $<0.001$ \\
\hline $\begin{array}{c}\text { Implantations after Operations other } \\
\text { than CABG and Valve }\end{array}$ & 5.967 & $2.039-17.466$ & 0.001 \\
\hline
\end{tabular}




\subsection{Characteristics of the Study Cohort after Excluding ECMO Patients :}

As previously mentioned, the hemodynamic data after ECMO implantation could not be assessed. In an effort to obtain earlier predictors of survival depending on available hemodynamic parameters and catecholamine requirements, patients with ECMO were excluded from the second statistical analysis. The characteristics of the remaining 117 patients are shown in Table 6 .

In the univariate analysis, various parameters were predictors of 30-day mortality (Table 7). While in the multivariate analysis, four parameters remained statistically significant. These parameters were MAP at 6 hours, adrenaline dose at 6 hours, CVP at 6 hours, and blood lactate concentration at 6 hours of IABP use (Table 8). From these variables, a new IABP score was calculated, designated Bad Oeynhausen IABP score, to predict death or survival in our cohort of patients.

The new IAPB score was calculated as follows: I (AD >0.04 $\mathrm{\mu g} / \mathrm{kg}$ body weight/min) + I (MAP $<60 \mathrm{~mm} \mathrm{Hg})+$ I (CVP $>14 \mathrm{~mm} \mathrm{Hg})+$ I(Lactate $>6 \mathrm{mmol} / \mathrm{l})$, whereas $\mathrm{I}(\mathrm{X})$ denotes the indicator function, being equal to one, only if $x$ holds true, and otherwise substitute zero.

Figure 4 demonstrates the accuracy of the newly developed score system to discriminate between survivors and non survivors. Patients who scored 3 or 4 points had no probability of surviving 30 days, whereas patients with a score of zero had a survival probability of $84.4 \%$. The area under the ROC curve was $0.81(0.72-0.90)$.

After developing the score system, another 145 patients, who received IABP intra-or postoperatively from January 2004 through December 2005, were evaluated prospectively. The types 
of operations performed in this control group are shown in Table 10. The probability of survival according to the score is shown in Figure 5. According this data, the investigation confirmed the validity of the score. Notably, the control group of patients included only one patient who survived the first 30 days with a score of 3. However, this patient needed long term nursing care, which is why we consider our new score to be highly accurate and predictable.

In Table 9 and Figure 6 A-D, differences amongst hemodynamic parameters are shown for patients who survived 30 days after operation and non survivors. Only the survivors showed a significant increase in MAP and CI values. The other parameters remained unchanged. However, CVP was significantly higher in the non survivors, compared to survivors before IABP implantation $(p=0.05)$. With the exception of the mPAP values, all other parameters differed significantly at the 24 hour interval between survivors and non-survivors.

Regarding catecholamine and their relation to 30 day mortality, dopamine and epinephrine dosage were the most important predictors, with significant difference in dopamine requirement starting early before IABP implantation. Patients who required dopamine doses $\geq 7 \mathrm{\mu g} / \mathrm{kg} / \mathrm{min}$ before IABP implantation had 52\% thirty day mortality versus $30.6 \%$ in patients with preimplantation dopamine of $<7 \mu \mathrm{g} / \mathrm{kg} / \mathrm{min}(p=0.02)$, yet epinephrine requirement before implantation was not statistically significant $(p=0.17)$. Patients with dopamine requirement of $\geq 8.5 \mu \mathrm{g} / \mathrm{kg} / \mathrm{min}$ one hour following implantation had $60.5 \%$ thirty day mortality versus $28.9 \%$ in the other group of patients with dopamine $<8.5 \mu \mathrm{g} / \mathrm{kg} / \mathrm{min}(p=0.002)$. Moreover, 30 day mortality in patients with epinephrine doses of $\geq 0.05$ $\mu \mathrm{g} / \mathrm{kg} / \mathrm{min} 1$ hour after implantation was $65.2 \%$ versus 33\% in patients with epinephrine doses $<0.05 \mu \mathrm{g} / \mathrm{kg} / \mathrm{min}(p=0.008)$. 
Meanwhile, statistically significant differences in dobutamine and norepinephrine requirements between survivors and non survivors could be detected only 24 hours following implantation. 
Table 6: Characteristics of the study cohort after excluding ECMO patients

\begin{tabular}{|c|c|c|}
\hline \multirow[t]{2}{*}{ Parameter } & Total & Percentage \\
\hline & \multicolumn{2}{|l|}{ Number } \\
\hline \multicolumn{3}{|l|}{ Sex } \\
\hline Male & 60 & 51.28 \\
\hline Female & 57 & 48.71 \\
\hline Age $\geq 70$ years & 65 & 55.55 \\
\hline \multicolumn{3}{|l|}{ Type of Operation } \\
\hline Coronary Artery Bypass Grafting & 62 & 52.99 \\
\hline Valve & 23 & 19.65 \\
\hline Combined coronary artery bypass grafting and valve & 29 & 24.78 \\
\hline Others & 3 & 2.56 \\
\hline \multicolumn{3}{|l|}{ Concomitant Diagnosis } \\
\hline Diabetes mellitus & 40 & 34.18 \\
\hline Atrial Fibrillation & 26 & 22.22 \\
\hline Left Main Stem Stenosis $\geq 70 \%$ & 22 & 18.80 \\
\hline Myocardial Infarction within 4 Weeks Before Surgery & 25 & 21.36 \\
\hline Emergency Operation & 19 & 16.23 \\
\hline Redos & 30 & 25.64 \\
\hline Preoperative Renal Insufficiency & 11 & 9.40 \\
\hline Preoperative Dialysis & 5 & 4.27 \\
\hline Peripheral Vascular Disease & 27 & 23.07 \\
\hline \multicolumn{3}{|l|}{ Indication for IABP use } \\
\hline Low Cardiac Output Syndrome & 40 & 34.18 \\
\hline During Cardiopulmonary Resuscitation & 33 & 28.20 \\
\hline Failure to Wean from Cardiopulmonary Bypass & 34 & 29.05 \\
\hline Others & 10 & 8.54 \\
\hline Preoperative NYHA functional class & 4 & 3.41 \\
\hline I & 17 & 14.52 \\
\hline II & 70 & 59.82 \\
\hline III & 26 & 22.22 \\
\hline \multicolumn{3}{|l|}{ IV } \\
\hline $\begin{array}{l}\text { Left ventricular ejection fraction } \\
\quad \leq 35 \%\end{array}$ & 20 & 17.09 \\
\hline
\end{tabular}


Table 7: Results of Univariate Analysis after Excluding ECMO Patients and Including Hemodynamic Data and Catecholamine Requirements

\begin{tabular}{|c|c|c|c|}
\hline Parameter & $\operatorname{Exp}(B)$ & 95응 CI for $\operatorname{Exp}(B)$ * & P-value \\
\hline Female sex & 1.786 & $1.001-3.189$ & 0.05 \\
\hline Age $\geq 70$ years & 2.092 & $1.136-3.854$ & 0.018 \\
\hline Body Mass Index (BMI) $\leq 28 \mathrm{~kg} / \mathrm{m}^{2}$ & 2.305 & $1.033-5.139$ & 0.041 \\
\hline CABG Operation & 0.523 & $0.293-0.933$ & 0.028 \\
\hline Valve Operation & 1.73 & $0.899-3.33$ & 0.1 \\
\hline Implantation in the Intensive Care Unit & 2.043 & $1.042-4.006$ & 0.038 \\
\hline Implantation During Resuscitation & 2.352 & $1.317-4.201$ & 0.004 \\
\hline $\begin{array}{l}\text { Dopamine Dose Immediately Before IABP Use } \\
\geq 7 \mathrm{\mu g} / \mathrm{kg} \mathrm{BW} / \mathrm{min} .\end{array}$ & 1.956 & $1.092-3.505$ & 0.024 \\
\hline MAP at $1 \mathrm{~h} \leq 65 \mathrm{~mm} \mathrm{Hg}$ & 2.89 & $1.43-5.841$ & 0.003 \\
\hline CVP at $1 \mathrm{~h} \geq 12 \mathrm{~mm} \mathrm{Hg}$ & 2.858 & $1.276-6.404$ & 0.011 \\
\hline $\mathrm{mPAP}$ at $1 \mathrm{~h} \geq 30 \mathrm{~mm} \mathrm{Hg}$ & 2.35 & $1.18-4.68$ & 0.015 \\
\hline $\begin{array}{l}\text { Dopamine Dose at } 1 \mathrm{~h} \\
\geq 8.5 \mu \mathrm{g} / \mathrm{kg} \mathrm{BW} / \mathrm{min} .\end{array}$ & 2.744 & $1.527-4.93$ & 0.001 \\
\hline $\begin{array}{l}\text { Adrenaline dose at } 1 \mathrm{~h} \\
\geq 0.05 \mathrm{\mu g} / \mathrm{kg} \mathrm{BW} / \mathrm{min} .\end{array}$ & 2.841 & $1.526-5.288$ & 0.001 \\
\hline Urine Volume at $1 \mathrm{~h} \leq 100 \mathrm{ml} / \mathrm{h}$ & 1.694 & $0.931-3.083$ & 0.085 \\
\hline MAP at $6 \mathrm{~h} \leq 60 \mathrm{~mm} \mathrm{Hg}$ & 3.855 & $2.095-7.093$ & $<0.001$ \\
\hline CVP at $6 \mathrm{~h} \geq 14 \mathrm{~mm} \mathrm{Hg}$ & 3.8 & $1.941-7.441$ & $<0.001$ \\
\hline PAWP at $6 \mathrm{~h} \geq 23 \mathrm{~mm} \mathrm{Hg}$ & 3.65 & $1.60-8.29$ & 0.002 \\
\hline $\mathrm{mPAP}$ at $6 \mathrm{~h} \geq 32 \mathrm{~mm} \mathrm{Hg}$ & 2.12 & $1.11-4.07$ & 0.023 \\
\hline $\begin{array}{l}\text { Dopamine Dose at } 6 \mathrm{~h} \\
\geq 7.5 \mu \mathrm{g} / \mathrm{kg} \mathrm{BW} / \mathrm{min} .\end{array}$ & 2.008 & $1.095-3.682$ & 0.024 \\
\hline $\begin{array}{l}\text { Adrenaline Dose at } 6 \mathrm{~h} \\
\geq 0.04 \mathrm{\mu g} / \mathrm{kg} \mathrm{BW} / \mathrm{min} .\end{array}$ & 3.817 & $2.064-7.061$ & $<0.001$ \\
\hline Urine Volume at $6 \mathrm{~h} \leq 50 \mathrm{ml} / \mathrm{h}$ & 3.204 & $1.774-5.787$ & $<0.001$ \\
\hline Blood Lactate at $6 \mathrm{~h} \quad \geq 6 \mathrm{mmol} / \mathrm{l}$ & 2.364 & $1.286-4.347$ & 0.006 \\
\hline $\mathrm{MAP}$ at $12 \mathrm{~h} \leq 65 \mathrm{~mm} \mathrm{Hg}$ & 3.122 & $1.669-5.843$ & $<0.001$ \\
\hline CVP at $12 \mathrm{~h} \geq 12 \mathrm{~mm} \mathrm{Hg}$ & 3.21 & $1.418-7.268$ & 0.005 \\
\hline $\mathrm{mPAP}$ at $12 \mathrm{~h} \geq 28 \mathrm{~mm} \mathrm{Hg}$ & 1.995 & $1.04-3.825$ & 0.038 \\
\hline PAWP at $12 \mathrm{~h} \geq 18 \mathrm{~mm} \mathrm{Hg}$ & 2.846 & $1.5-5.402$ & 0.001 \\
\hline $\begin{array}{l}\text { Dopamine Dose at } 12 \mathrm{~h} \\
\geq 7 \mathrm{\mu g} / \mathrm{kg} \mathrm{BW} / \mathrm{min} .\end{array}$ & 2.114 & $1.136-3.937$ & 0.018 \\
\hline Epinephrine need at $12 \mathrm{~h}$ & 3.155 & $1.684-5.913$ & $<0.001$ \\
\hline MAP at $24 \mathrm{~h} \leq 65 \mathrm{~mm} \mathrm{Hg}$ & 2.971 & $1.568-5.63$ & 0.001 \\
\hline CVP at $24 \mathrm{~h} \geq 12 \mathrm{~mm} \mathrm{Hg}$ & 2.959 & $1.301-6.728$ & 0.01 \\
\hline PAWP at $24 \mathrm{~h} \geq 18 \mathrm{~mm} \mathrm{Hg}$ & 2.646 & $1.37-5.111$ & 0.004 \\
\hline $\mathrm{CI}$ at $24 \mathrm{~h} \leq 2.4 \mathrm{~L} / \mathrm{min} / \mathrm{m}^{2}$ & 3.247 & $1.671-6.31$ & 0.001 \\
\hline $\begin{array}{l}\text { Dopamine Dose at } 24 \mathrm{~h} \\
\geq 7 \mathrm{\mu g} / \mathrm{kg} \mathrm{BW} / \mathrm{min} .\end{array}$ & 2.917 & $1.531-5.557$ & 0.001 \\
\hline Epinephrine need at $24 \mathrm{~h}$ & 3.924 & $2.07-7.434$ & $<0.001$ \\
\hline
\end{tabular}

* $\operatorname{Exp}(\mathrm{B})=$ exponent of the B-coefficient; $\mathrm{CABG}=$ Coronary Artery Bypass Graft;

$\mathrm{MAP}=$ Mean Arterial Pressure; $\mathrm{BW}=$ Body Weight; $\mathrm{CI}=$ Cardiac Index; $\mathrm{CVP}=$ Central Venous Pressure; PAWP = Pulmonary Artery Wedge Pressure; mPAP = mean Pulmonary Artery Pressure 
Table 8: Results of Multivariate Analysis after Excluding ECMO Patients

\begin{tabular}{|lccc|}
\hline Parameter & Exp (B) & 95\% CI of Exp (B) * & P-value \\
\hline CVP at $6 \mathrm{~h} \geq 14 \mathrm{~mm} \mathrm{Hg}$ & 3.946 & $1.917-8.125$ & $<0.001$ \\
MAP at $6 \mathrm{~h} \leq 60 \mathrm{~mm} \mathrm{Hg}$ & 2.655 & $1.365-5.162$ & 0.004 \\
Adrenaline at $6 \mathrm{~h} \geq 0.04 \mathrm{\mu g} / \mathrm{kg} \mathrm{BW} / \mathrm{min}$ & 2.591 & $1.333-5.036$ & 0.005 \\
Lactate at $6 \mathrm{~h} \geq 6 \mathrm{mmol} / \mathrm{l}$ & 2.096 & $1.072-4.096$ & 0.030 \\
\hline
\end{tabular}

$\mathrm{BW}=$ Body Weight; $\mathrm{CVP}=$ Central Venous Pressure

Table 9: Hemodynamic Differences Between 30 Day Survivors and Non-survivors

\begin{tabular}{|c|c|c|c|}
\hline Hemodynamic & $\begin{array}{c}\text { Mean ( } \pm S D) \\
\text { Non-survivors }\end{array}$ & $\begin{array}{c}\text { Mean ( } \pm S D) \\
\text { Survivors }\end{array}$ & Value* \\
\hline MAP (Pre) & $55 \quad(11.7)$ & $55 \quad(11)$ & 0.9 \\
\hline CVP (Pre) & 15 (5) & $13.1(4.3)$ & 0.05 \\
\hline mPAP (Pre) & 31 (8) & $28.1(5.5)$ & 0.5 \\
\hline PAWP (Pre) & $19.6(6)$ & $18.4 \quad(2.5)$ & 0.8 \\
\hline CI (Pre) & $1.93(0.3)$ & $2(0.4)$ & 0.3 \\
\hline MAP (1) & $57.62(12.8)$ & $66.86 \quad(11.7)$ & $<0.001$ \\
\hline CVP (1) & $14.62(3.5)$ & $12.6(3.6)$ & 0.004 \\
\hline mPAP (1) & $29.14 \quad(7.12)$ & $25.9 \quad(4.1)$ & 0.02 \\
\hline PAWP (1) & 17.52 (5) & $15.56(3.94)$ & 0.06 \\
\hline CI (1) & $2.32 \quad(0.77)$ & $2.42(0.57)$ & 0.5 \\
\hline $\operatorname{MAP}(6)$ & $62.21(10.73)$ & $70 \quad(8.8)$ & $<0.001$ \\
\hline CVP (6) & $15.26(3.76)$ & 12 (3) & $<0.001$ \\
\hline mPAP (6) & $29.67 \quad(7.81)$ & $26.66(4.75)$ & 0.03 \\
\hline PAWP (6) & $17.37 \quad(4.98)$ & 14.63 (4) & 0.005 \\
\hline CI (6) & $2.38 \quad(0.78)$ & $2.63(0.6)$ & 0.09 \\
\hline MAP (12) & $65(14.4)$ & $73.7 \quad(10.94)$ & 0.002 \\
\hline CVP (12) & $14.57 \quad(3)$ & $11.97 \quad(3.5)$ & $<0.001$ \\
\hline mPAP (12) & $29.78 \quad(7.57)$ & $25.9 \quad(6.56)$ & 0.01 \\
\hline PAWP (12) & $17.68 \quad(5.85)$ & $14.53(4.42)$ & 0.006 \\
\hline CI (12) & $2.6 \quad(0.66)$ & $2.76 \quad(0.5)$ & 0.18 \\
\hline MAP (24) & $66.26(11.75)$ & $74 \quad(9.52)$ & $<0.001$ \\
\hline CVP (24) & $14.55 \quad(3.47)$ & $11.66 \quad(3.38)$ & $<0.001$ \\
\hline mPAP & $28.61 \quad(6.96)$ & $26.67 \quad(6.58)$ & 0.18 \\
\hline PAWP (24) & 17.86 (5) & $15.2(4.33)$ & 0.01 \\
\hline CI (24) & $2.74 \quad(0.66)$ & $3.16(0.6)$ & 0.002 \\
\hline
\end{tabular}


Table 10: Type of Operation Performed in the Control Group of Patients (2004 and 2005)

\begin{tabular}{|c|c|c|}
\hline Operation & Total Number Performed & Percentage \\
\hline $\mathrm{CABG}^{*}$ & 106 & 73.10 \\
\hline Valve Operation & 21 & 14.48 \\
\hline CABG + Valve Operation & 16 & 11.03 \\
\hline VSD closure & 2 & 1.42 \\
\hline Total & 145 & 100.00 \\
\hline
\end{tabular}

${ }^{*} \mathrm{CABG}=$ Coronary Artery Bypass Graft; $\mathrm{VSD}=$ Ventricular Septal Defect

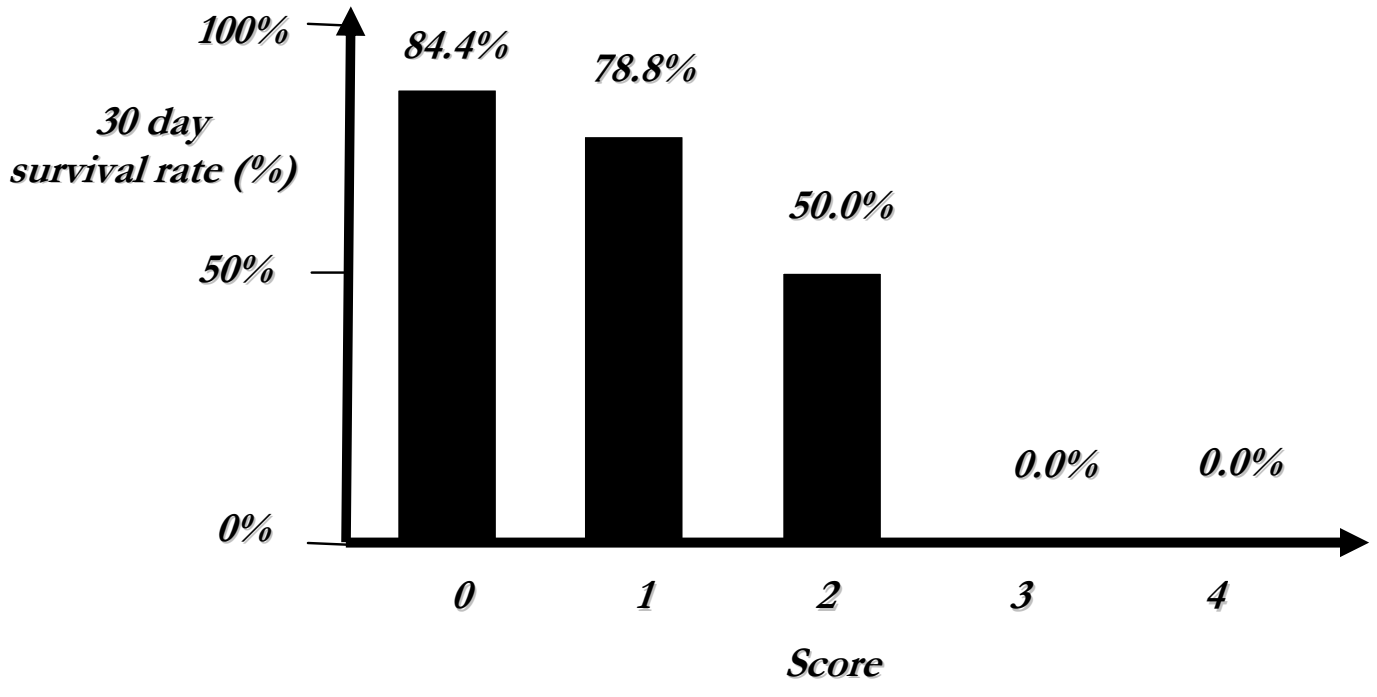

$\begin{array}{llllll}\% \text { of patients } \quad 29.6 & 30.6 & 24.1 & 11.1 & 4.6\end{array}$

$$
n=117
$$

Figure 4: Probability of 30 Days Survival According to the New Scoring System 


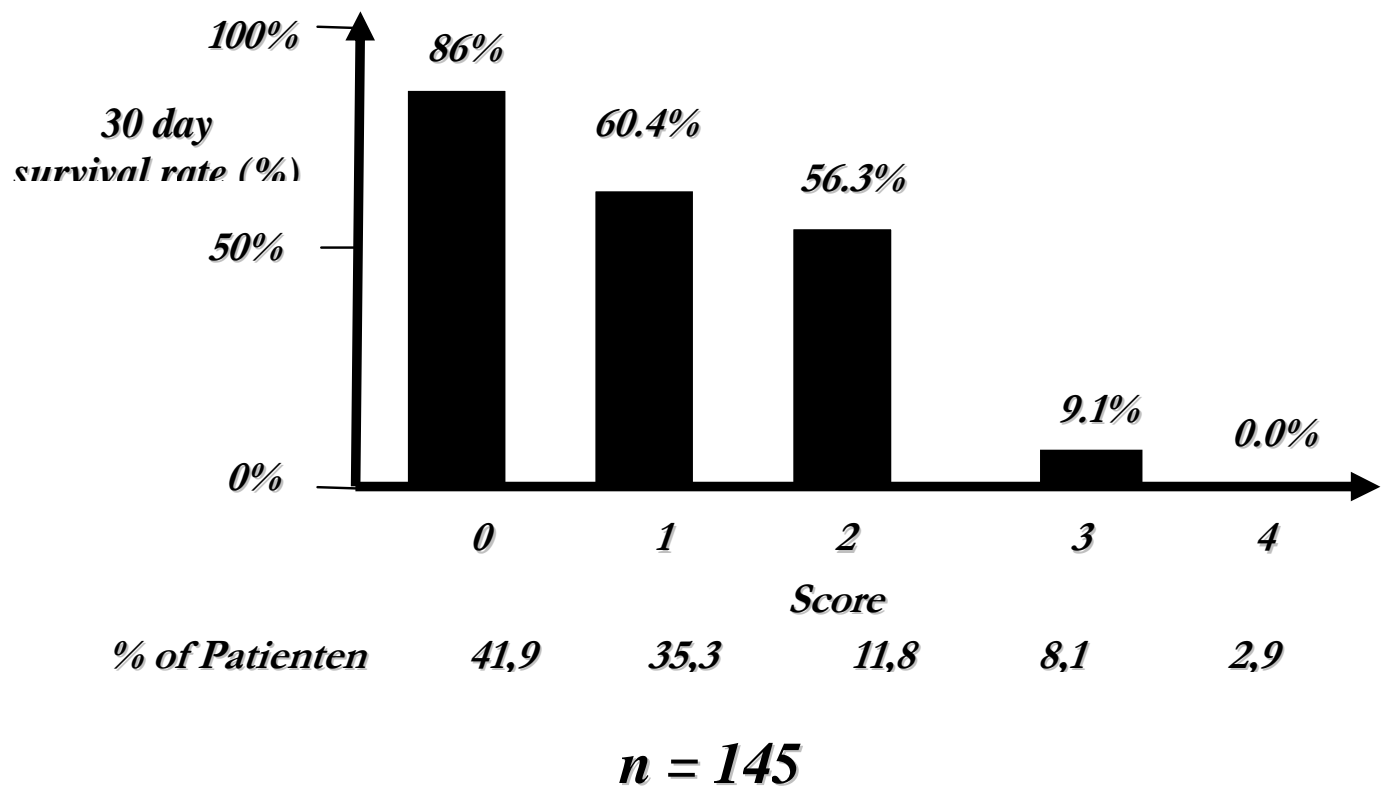

Figure 5: Probability of Survival after Prospective Score Evaluation (2004-2005)

MAP (mm Hg)

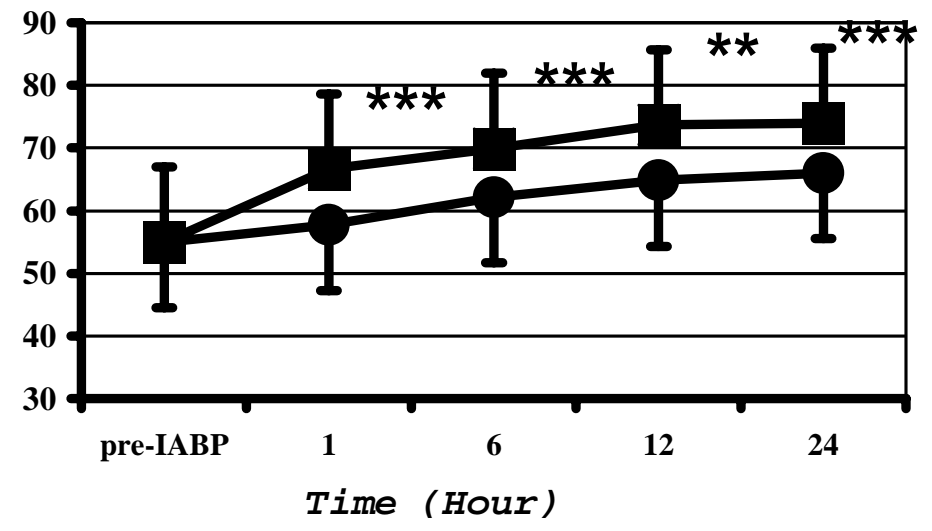

Figure 6-A 


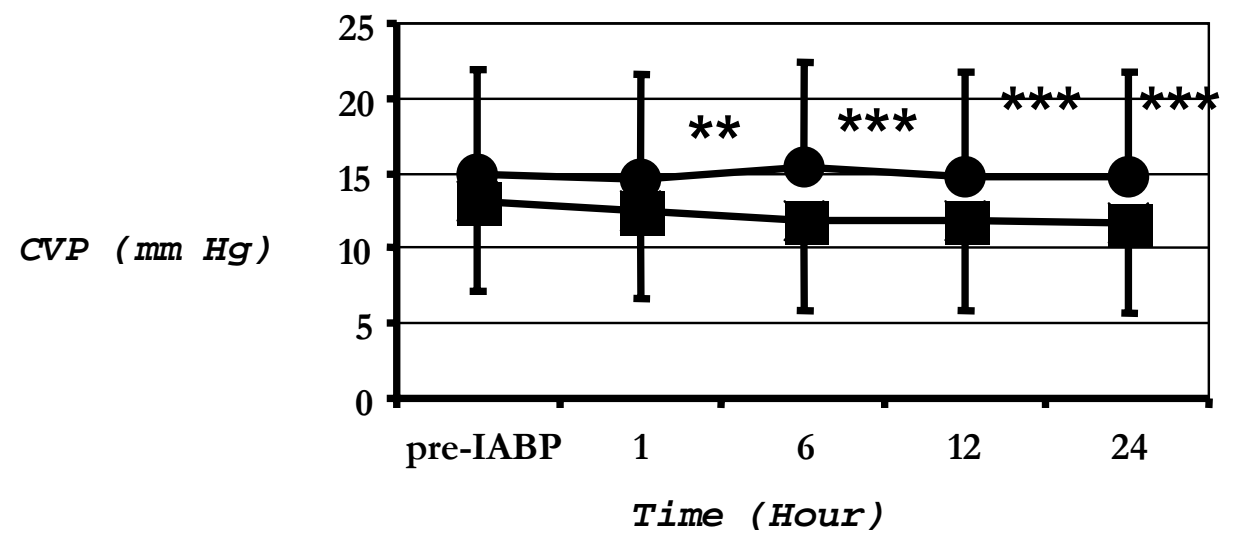

Figure 6-B

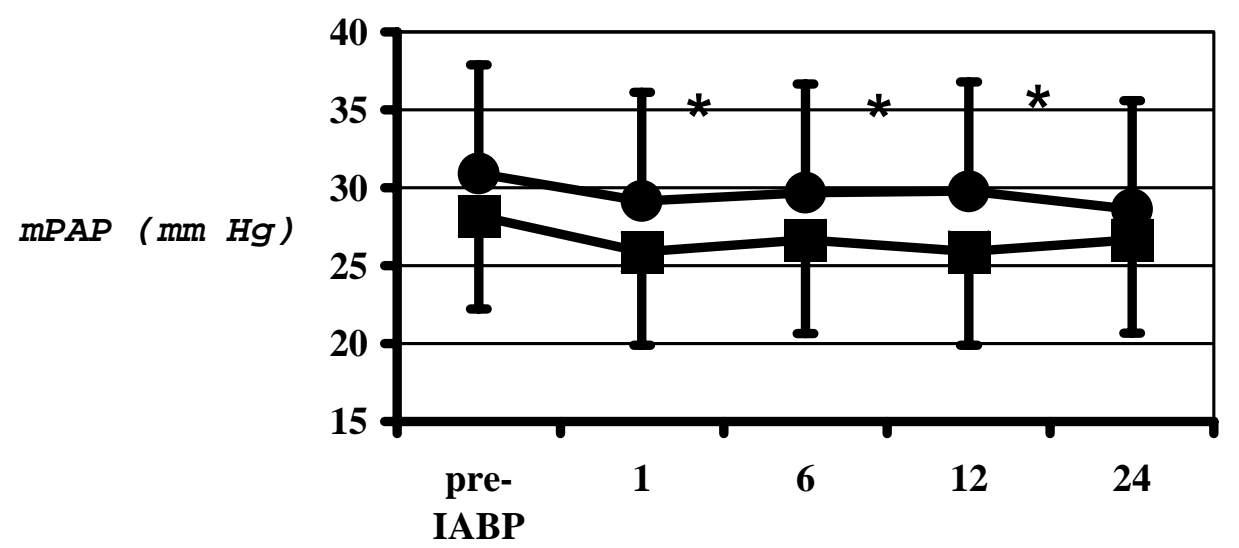

Time (Hour)

Figure 6-C 


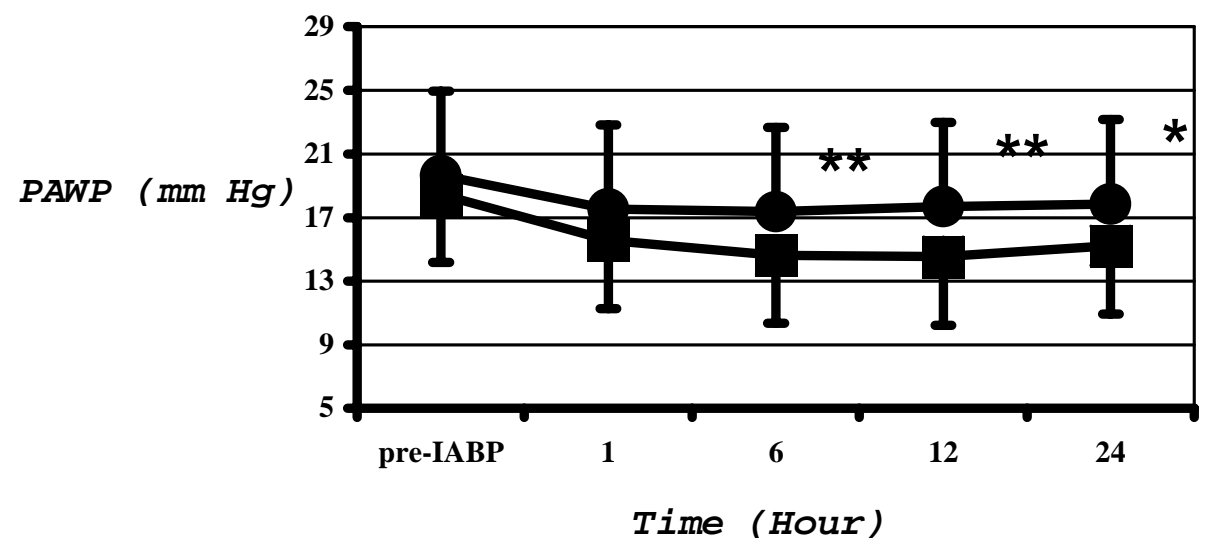

Figure 6-D

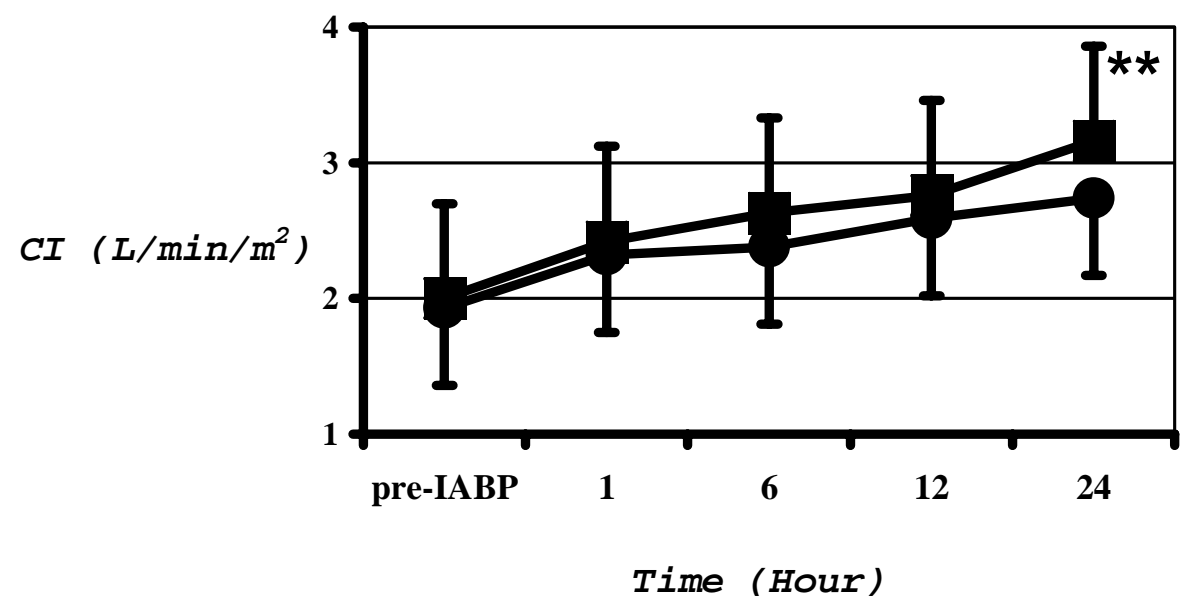

Figure 6-E

Figure $6 \boldsymbol{A}-\boldsymbol{E}:$ Mean arterial pressure (A) and hemodynamics (B-E) of survivors and non survivors during the first 24 hours after IABP implantation; Data are given as mean +/- standard

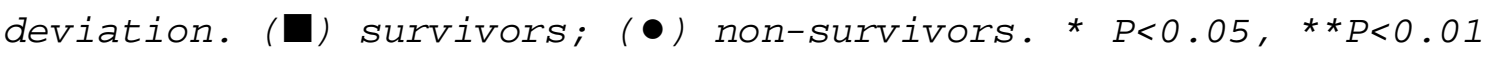
$\star * \star P<0.001$ vs. survivors at the same time point (Unpaired student $t-$ test). 


\section{Comment}

Despite continuous improvement in surgical and anaesthetic techniques, including myocardial protection, the morbidity and mortality of this group of patients who require intra and /or postoperative IABP remains high.

In this study, 62 patients (44.28\%) died in the ICU. The 30 day mortality rate was $45.7 \%$, a value which is comparable to the mortality rates of $21-73 \%$ in other reported studies (Baskett et al., 2002; Creswell et al., 1995; Ghali et al., 1999). Overall, only 1.77\% from the entire patient group received IABP either intra or perioperatively, and $30.7 \%$ of implantations were done on emergency basis in the ICU during CPR either due to VF or asystole.

Nearly all published studies have demonstrated that patients receiving preoperative IABPs have better outcomes than those receiving IABPs intraoperatively or postoperatively (Ali et al., 2005; Creswell et al., 1995; Gutfinger et al., 1999; Holman et al., 2000; Pfeiffer et al., 2005; Ramnarine et al., 2005). Yet, this study includes patients who have received IABPs both intraoperatively and postoperatively, which also contributes to the relative high mortality rate after long term follow up.

After 1 year follow up, the mortality rate was 55.71\% ( $\mathrm{n}=78)$, while the 2 year mortality rate was $58.57 \%(\mathrm{n}=82)$. Considering these high mortality rates, it is enormously important to identify any factor which predicts mortality in these patients.

There are several factors, reported in other studies, that predict survival such as higher age, female gender, preoperative renal insufficiency, myocardial infarction in the last 4 weeks, preoperative nitro-glycerine use, preoperative reduced left ventricular ejection fraction, LVEDP, NYHA class, combined CABG and valve operations, prolonged $\mathrm{CPB}$ and $\mathrm{ACC}$ time, small balloon size, transthoracic insertion, prolonged duration 
of support, postoperative use of isoproterenol or digoxin, perioperative myocardial infarction, the need for dialysis, postoperative high lactate level in first 8 hours of implantation (Baldwin et al., 1993; Corral et al., 1986; Davies et al., 2001; Hedenmark et al., 1989; Naunheim et al., 1992; Pi et al., 1995; Scanlon et al., 1976; Sturm et al., 1980). Moreover, Norman et al. and Hausmann et al. developed scoring systems to predict mortality in these patients (Hausmann et al., 2001; Norman et al., 1977).

Regarding the predictors of survival in this study, maximal level of CK-MB could be recognized as an important factor ( $p=$ $0.004, \mathrm{RR}=1.001)$. Ultimately, this reflects the degree of cardiac damage in these patients, especially a maximal CK-MB level of $520 \mathrm{U} / \mathrm{L}$ which predicted 100\% mortality regardless of the preoperative left ventricular ejection fraction. In addition, the postoperative maximal troponin level was significant in univariate analysis, but it was not predictive in multivariate analysis.

The type of operation performed was another important factor which predicted survival in these patients requiring IABP. This can be observed from the differences in the mortality rates. The 30 day mortality rate was $35.5 \%, 55.6 \%, 54.5 \%$ and 100\% for CABG, valve, CABG + valve, and other operations, respectively. The worst outcome seen in patients receiving IABP after operations other than CABG and valve operation was one of the important factors contributing to mortality in this cohort $(p=0.001, \mathrm{RR}=5.967)$. Moreover, the outcome was better in patients who received IABP after CABG than after valve operation. This result is also reported in other studies (Baskett et al., 2002; Ota et al., 1992). 
Among other important factors, postoperative renal insufficiency is considered to be highly predictive ( $p=<0.001$, $\mathrm{RR}=4.312)$. The important reported causes of postoperative renal insufficiency are low output state and hypotension or potent vasopressor use. The previously described risk factors for development of postoperative renal insufficiency include: pre-existing renal dysfunction, older age, left ventricular dysfunction, emergency operation, as well as any combination of the following: hypertension, diabetes and peripheral vascular disease, concomitant CABG-valve operations, mitral valve operations, use of deep hypothermic circulatory arrest, and longer duration of bypass and total cross clamp time (Andersson et al., 1993; Corwin et al., 1989; Gaudino et al., 2005; Khilji et al., 2004; Zanardo et al., 1994). Significant risk factors for development of postoperative renal insufficiency in this study includes: age $(p=0.009, R R=1.035)$, ECMO implantation $(p=<0.001, R R=2.910)$, paralytic ileus $(p=<0.001, R R=2.618)$, maximum lactate in first 24 hours ( $p=0.001, R R=1.061)$, and postoperative liver insufficiency $(p=0.03, R R=1.665)$.

Another important predictor was the occurrence of postoperative paralytic ileus due to non occlusive mesenteric ischemia ( $p=$ $0.001, \mathrm{RR}=2.389)$. This constitutes the most catastrophic gastrointestinal complication, following cardiac surgery with a high mortality rate (Mangi et al., 2005). In this study, $26.42 \%$ developed paralytic ileus, $41.7 \%$ of them required laparotomy, and mortality in these patients with ileus was very high (86.1\%). This mesenteric ischemia results from splanchnic hypoperfusion due to a low cardiac output state or a long pump run, atherosclerotic embolism, or mesenteric thrombosis less commonly. The known risk factors for the development of mesenteric ischemia include: peripheral vascular disease, triple vessel disease, operation type, history of smoking, IABP use, renal insufficiency, use of ionotropics, and prolonged 
cardiopulmonary and-or aortic cross clamp time (Ghosh et al., 2002; Venkateswaran et al., 2002). In this cohort of patients, age $(p=<0.001, R R=1.095), \operatorname{BMI}(p=0.005, R R=0.872)$, NYHA class $(p=0.017, R R=2.614)$, maximal lactate level in the first 24 hours ( $p=0.001, R R=1.1)$, and postoperative septicemia ( $p=$ $<0.001, R R=2.48)$ were important predictors of this lethal complication. The early diagnosis of this lethal complication is still difficult and can be made merely by mesenteric arteriography which can identify or exclude thromboembolic causes and allow for the infusion of mesenteric vasodilators (Papaverine) (Kaleya et al., 1992; Klotz et al., 2001). Furthermore, Straub et al. described CW-Doppler sonography to be helpful in the diagnosis of this complication (Straub et al., 2004).

Postoperative lactate levels in the first 24 hours, with metabolic acidosis, reflects the degree of tissue damage due to low cardiac output with peripheral vasoconstriction, poor peripheral perfusion, or intra-abdominal catastrophes, such as mesenteric ischemia secondary to low-flow state or renal causes. It is well known that the normal myocardium utilizes glucose and degrades lactate produced by glycolysis to pyruvate so that in normal heart at rest, no lactate is formed in the coronary sinus blood. Once myocardial hypoxia occurs, there is a decrease in aerobic glycolysis. As a result, anaerobic metabolism will ensue causing production of lactate. In this cohort of patients, serum lactate levels were identified to be highly predictive of mortality. Lactate levels after six hours of IABP implantation are an important parameter, which are also included in the newly developed Bad Oeynhausen scoring system. Davies et al. reported in a small group of patients with maximal level of lactate in the first 8 hours after IABP implantation of $10 \mathrm{mmol} / \mathrm{L}$ to be a $100 \%$ predictor of mortality (Davies et al., 2001). Moreover, MAP less than $60 \mathrm{~mm} \mathrm{Hg}$ just 
eight hours after IABP implantation was approximately 90\% predictive of in-hospital mortality. Compared to this study, MAP values less than $60 \mathrm{~mm}$ Hg after 6 hours of IABP showed only 69\% predictive values for mortality. Regarding lactate levels, $100 \%$ mortality was achieved only if the concentrations were higher than $16 \mathrm{mmol} / \mathrm{L}$. Data support the medical progress in the treatment of patients with severe cardiac complications as well as different treatment strategies at different heart centres.

The above mentioned factors are essential to consider, but the fact that they occur relatively late in follow up instigated a search for other predictive variables, which are available early after IABP implantation, and can be included in a score system. This might help the anesthesiologist/surgeon to find an optimal patient-specific treatment. Information could be achieved in this study through inclusion of hemodynamic parameters and catecholamine requirements early after IABP implantation. Yet for this purpose, patients with ECMO had to be excluded from the second statistical analysis.

A newly developed Bad Oeynhausen IABP score demonstrated reliability in prediction of the 30-day survival in this cohort of patients. It is noteworthy that all parameters of the Bad Oeynhausen IABP score can be assessed easily and do not need the use of a Swan-Ganz catheter.

All four parameters of the Bad Oeynhausen IABP score may indicate cardiac dysfunction. The need for high adrenaline doses as well as low MAP values are indicators of low cardiac output, whereas high CVP values reflect right ventricular dysfunction either primarily or secondarily due to left ventricular dysfunction. Moreover, high lactic acid concentrations can result from low cardiac output. 
The higher incidence of several complications such as paralytic ileus, laparotomy, septicemia, and postoperative renal insufficiency in the non-survivors compared to the patients who survived the first 30 days may also have been influenced by the more pronounced cardiac dysfunction of the non-survivors.

Hausmann and associates demonstrated the results of a clinical study aimed to discover predictors of survival in patients after IABP implantation (Hausmann et al., 2002; Hausmann et al., 2001). A scoring system was developed that includes the adrenaline requirement, left atrial pressure, urine output, and mixed venous saturation $\left(\mathrm{SvO}_{2}\right)$, beginning just one hour after IABP implantation. However, this scoring system was not able to predict the mortality in Heart centre Bad Oeynhausen, simply because no patients had more than 3 points from a total of 5 points (which then predicts 100\% mortality). Maximum adrenaline dose in Heart Centre Bad Oeynhausen was <0.3 $\mu \mathrm{g} / \mathrm{kg} / \mathrm{min}$, whereas the Hausmann score system which depicts that two points can be obtained from an adrenaline dose of $\geq 0.5 \mu \mathrm{g} / \mathrm{kg} / \mathrm{min}$. These results explain the differences in therapy strategies between the Heart Centres. However, apart from $\mathrm{SvO}_{2}$, the other parameters of the Hausmann IABP score were also predictors in this study for the univariate analysis, at least 6 hours after IABP implantation. $\mathrm{SvO}_{2}$ can be used to asses the adequacy of tissue perfusion and oxygenation, and to serve as an indirect predictor of low cardiac output. It has been reported that $\mathrm{SvO}_{2}$ measurement is unreliable and insensitive method of predicting cardiac output (Sommers et al., 1993). This stems from consistent fluxation amongst factors that affect oxygen supply and demand, such as shivering, low temperature, anaemia, alteration in $\mathrm{FiO}_{2}$ and the efficiency of alveolar gas exchange. 
A rise in filling pressure (PAWP) or left atrial pressure to about 18-20 mm Hg will optimize the preload required to achieve a satisfactory cardiac output, but on the other hand, it reflects low ventricular performance. Left atrial pressure in the low $20 \mathrm{~s}$ is recommended usually for patients with poor left ventricular function, a stiff hypertrophied ventricle with diastolic dysfunction, a small left ventricular chamber, or pre-existing pulmonary hypertension from mitral valve disease. A high LAP is one of the important parameters in the Hausmann scoring system, with LAP $\geq 15 \mathrm{~mm}$ Hg being highly predictive. In our study, PAWP recorded one hour after implantation was not a significant parameter. Elevation in PAWP after the sixth hour from implantation was significant in univariate analysis.

Regarding changes in cardiac index (CI) following IABP implantation, a significant difference between survivors and non survivors starts relatively late in follow up (after 24 hours). This fact is also mentioned in some other studies (Ida et al., 1984; Nasu et al., 1991). However, CI $\leq 2.4 \mathrm{~L} / \mathrm{min} . / \mathrm{m}^{2}$ about 24 hours after implantation was significant only in univariate analysis with no effect in multivariate analysis. Therefore it is not possible to rely on cardiac index alone as a predictive mortality parameter early in the follow up.

Mean arterial pressure (MAP) is an extremely sensitive factor predicting survival in this study. There is a continuous significant difference in mean arterial pressure throughout the course of follow up between survivors and non survivors. This can be explained by the indirect relation of the arterial pressure to the cardiac output and systemic vascular resistance (Blood Pressure $=$ Cardiac Output $x$ Systemic Vascular Resistance). However in the early postoperative period, myocardial function may be marginal despite normal or elevated blood pressure due to an elevated SVR resulting from augmented 
sympathetic tone and peripheral vasoconstriction. Ultimately, a deterioration in blood pressure indirectly reflects marginal cardiac output. It has been recognized that the myocardial function generally declines for about $6-8$ hours following cardiac surgery, presumably from ischemic/ reperfusion injury before returning to baseline after 24 hours (Breisblatt et al., 1990), and it is obvious in this study that deterioration might be worse in patients who require IABP after cardiac surgery. Moreover, low blood pressure will cause systemic hypoperfusion leading to end organ dysfunction. Among the most important organ systems affected which influences survival are myocardial, cerebral, renal, and mesenteric blood supply, resulting in ischemia and organ dysfunction. It is noteworthy that MAP and CI increased significantly during the first 24 hours only in the survivors of this study cohort.

The severe damage of the heart in these patients also becomes obvious by the observation that the hemodynamic parameters showed significant differences between survivors and nonsurvivors already within the first 24 hours of IABP use. Data further suggests that patients with profound hemodynamic compromise persisting after IABP implantation will likely survive only with a VAD system (Baldwin et al., 1993; Torchiana et al., 1997). In this study cohort, only a few patients with intra or postoperative IABP ultimately received a VAD system. Furthermore, it is difficult to rule out that 30-day survival would have been enhanced if more patients had received a VAD system. At present, VAD implantation in Heart Centre Bad Oeynhausen is performed in patients who fail to recover after ECMO implantation, in patients with end-stage heart failure, or in patients with fulminant myocarditis.

It is also important to consider the catecholamine requirements in the early hours after IABP implantation, because they 
reflect a pertinent dichotomy. On one hand, it suggests the degree of hemodynamic deterioration, while on the other hand higher doses lead to more drug related complications. The higher mortality in patients with greater catecholamine requirement is documented in some other studies (Hausmann et al., 2002; Nasu et al., 1991). Among the most important catecholamines in this study are dopamine and epinephrine, which were significant throughout the follow up time. Epinephrine requirement from $\geq 0.04 \mu \mathrm{g} / \mathrm{Kg} \mathrm{BW} / \mathrm{min}$ six hours following implantation is one of the most important predictive factors of mortality in these patients.

However, differences in kind and severity of complications in the patients of this study and the patients of earlier studies, as well as different treatment strategies may have influenced multivariate analysis differences. Both the differences in baseline characteristics between patient groups as well as the differences in treatment strategies may make it difficult to develop a generally applicable IABP score. At present, it seems that each Heart Centre has to develop its own IABP score.

IABP related complications were recorded in 5\%. This low complication rate stems from the fact that $94.3 \%$ of the implantations were percutaneous, using seldinger technique. Open surgical implantation was used only in four patients (2.85\%), while four implantations (2.85\%) were transthoracic. Another important contributing factor is the use of smaller catheters in this series ( 8 French). Elahi et al. demonstrated significant decrease in IABP related complication rate in the last years due to the increasing number of IABP used, evolving technology in IABP design, less invasive insertion techniques, and appropriate anticoagulation therapy (Elahi et al., 2005). Previously described risk factors for IABP related complications include female sex, peripheral vascular disease, 
diabetes mellitus, duration of IABP support, smoking, and hypertension (Gottlieb et al., 1984; Cohen et al., 2000; Miller et al., 1992). None of the aforementioned risk factors were significant in this series of patients, but lactate level $\geq 6$ mmol/L in the first 6 hours of IABP implantation was an independent risk factor of IABP related complications ( $p=$ $0.013)$.

In summary, our data demonstrate that a score can be helpful to predict 30 day lethality of patients with intra or postoperative IABP implantation. In order to develop a generally applicable IABP score, it is necessary that there is easy access to essential parameters. However, before such a generally applicable score can be developed, uniform recommendations for preoperative, intraoperative, and postoperative IABP use and treatment strategies must exist. The fact that myocardial function declines for about 6-8 hours following cardiac surgery (presumably from ischemic/ reperfusion injury) (Breisblatt et al., 1990) might further confirm the applicability of the new score system, since the risk factors presented several hours after IABP implantation were more reliable to predict the mortality as factors available immediately after implantation.

This study represents four years of experience in a quaternary level Heart Centre. Moreover, data are in general agreement with the results of recently published studies (Davies et al., 2001; Hausmann et al., 2002). Although satisfactory results could be demonstrated in these patients, they continue to have high mortality, especially patients receiving IABP postoperatively. This may encourage insertion of IABP early before the operation in patients with multiple risk factors (Baskett et al., 2002; Christenson et al., 1997; Christenson et al., 1997; Holman et al., 2000). The trends should favour 
prophylactic use to avoid rather than to treat ischemia, or else to think about other alternatives, for example, implementation of various VAD systems in the early postoperative period.

\section{Summary}

This study deals with patients receiving IABP intra and/ or postoperatively following cardiac operations. Generally, these patients have a high mortality rate even after implantation of this device. This study contains both retrospective and prospective elements, aimed to identify predictors of survival after IABP implantation, which may be helpful to adjust the future management strategy.

Significant risk factors in this study were as follows: implantation after operations other than CABG and valve operations, postoperative high levels of lactate and/ or CK/MB levels, postoperative complications such as renal insufficiency and ischemic paralytic ileus.

After excluding patients who received ECMO, the parameters available within the first twenty-four hours after IABP implantation were tested by Cox regressions analysis to pinpoint independent risk factors which could be included in a new score system. Mean arterial pressure (MAP), central venous pressure (CVP), lactate levels and epinephrine requirement six hour after IABP implantation were the most significant factors in the multivariate analysis to predict the 30 day mortality. Based on this finding, a new Bad Oeynhausen scoring system could be developed which is able to predict a $100 \% 30$ day mortality by maximal score of 3 or 4 . The new IABP score was calculated as follows: I ( $\mathrm{AD} \geq 0.04 \mu \mathrm{g} / \mathrm{kg} / \mathrm{min})+\mathrm{I}(\mathrm{MAP} \leq 60 \mathrm{~mm} \mathrm{Hg})$ $+\mathrm{I}(\mathrm{CVP} \geq 14 \mathrm{~mm} \mathrm{Hg})+$ I (Lactate $\geq 6 \mathrm{mmol} / \mathrm{l})$, whereas $\mathrm{I}(\mathrm{X})$ denotes the indicator function, being equal to 1 if $\mathrm{X}$ holds and zero otherwise. 
After development of the aforementioned score system, the sensitivity and predictability were evaluated prospectively in another control group. The acquired results of this investigation confirmed the applicability of the score.

Lack of a previously developed score system, able to predict patient survival in Bad Oeynhausen Heart Centre, might be due to different treatment strategies in different Heart Centres. However it is advantageous to develop a generally applicable IABP score. Moreover, it is desirable that the parameters, which are needed to calculate such a score, can be assessed easily. Yet, before such a generally applicable score can be developed, uniform recommendations for preoperative, intraoperative, and postoperative IABP use and treatment strategies must exist.

The data in this study demonstrate that the Bad Oeynhausen score system predicts 30 day fatality in patients with IABP implantation. Such a score can be useful to find an optimal patient-specific treatment. Therefore, this new risk score will be used in the future to select patients, who probably will benefit from an early VAD implantation. 


\section{References}

Aksnes, J., M. Abdelnoor, E. S. Platou and N. B. Fjeld (1996). Mortality in patients supported by intra-aortic balloon pump in the course of cardiac surgery was related to perioperative myocardial infarction. Eur J Cardiothorac Surg 10, 408-11.

Alcan, K. E., S. H. Stertzer, E. Wallsh, M. S. Bruno and N. P. DePasquale (1984). Current status of intra-aortic balloon counterpulsation in critical care cardiology. Crit Care Med 12, 489-95.

Alcan, K. E., S. H. Stertzer, E. Wallsh, N. P. DePasquale and M. S. Bruno (1983). The role of intra-aortic balloon counterpulsation in patients undergoing percutaneous transluminal coronary angioplasty. Am Heart J 105, 527-30.

Ali, I. S. and K. J. Buth (2005). Preoperative statin use and in-hospital outcomes following heart surgery in patients with unstable angina. Eur J Cardiothorac Surg 27, 1051-6.

Alpert, J., V. Parsonnet, R. J. Goldenkranz, E. K. Bhaktan, D. K. Brief, B. J. Brener, I. Gielchinsky and R. M. Abel (1980). Limb ischemia during intra-aortic balloon pumping: indication for femorofemoral crossover graft. J Thorac Cardiovasc Surg 79, $729-34$.

Andersson, L. G., R. Ekroth, L. E. Bratteby, S. Hallhagen and O. Wesslen (1993). Acute renal failure after coronary surgery-a study of incidence and risk factors in 2009 consecutive patients. Thorac Cardiovasc Surg 41, 237-41.

Arafa, O. E., T. H. Pedersen, J. L. Svennevig, E. Fosse and O. R. Geiran (1999). Vascular complications of the intraaortic balloon pump in patients undergoing open heart operations: 15year experience. Ann Thorac Surg 67, 645-51.

Baldwin, R. T., S. Slogoff, G. P. Noon, M. Sekela, O. H. Frazier, S. K. Edelman and W. K. Vaughn (1993). A model to predict survival at time of postcardiotomy intraaortic balloon pump insertion. Ann Thorac Surg 55, 908-13.

Baskett, R. J., W. A. Ghali, A. Maitland and G. M. Hirsch (2002). The intraaortic balloon pump in cardiac surgery. Ann Thorac Surg 74, 1276-87.

Bregman, D. A. (1980). Clinical experience with percutaneous Intraaortic balloon pumping. Cardiovasc Dis 7, 318-324.

Breisblatt, W. M., K. L. Stein, C. J. Wolfe, W. P. Follansbee, J. Capozzi, J. M. Armitage and R. L. Hardesty (1990). Acute 
myocardial dysfunction and recovery: a common occurrence after coronary bypass surgery. J Am Coll Cardiol 15, 1261-9.

Christenson, J. T., F. Simonet, P. Badel and M. Schmuziger (1997). The effect of preoperative intra-aortic balloon pump support in patients with coronary artery disease, poor leftventricular function (LVEF < 40\%), and hypertensive LV hypertrophy. Thorac Cardiovasc Surg 45, 60-4.

Christenson, J. T., F. Simonet, P. Badel and M. Schmuziger (1997). Evaluation of preoperative intra-aortic balloon pump support in high risk coronary patients. Eur J Cardiothorac Surg 11, 1097-103; discussion 1104 .

Christenson, J. T., F. Simonet, P. Badel and M. Schmuziger (1999). Optimal timing of preoperative intraaortic balloon pump support in high-risk coronary patients. Ann Thorac Surg 68, 934-9.

Cohen, M., M. S. Dawson, C. Kopistansky and R. McBride (2000). Sex and other predictors of intra-aortic balloon counterpulsation-related complications: prospective study of 1119 consecutive patients. Am Heart J 139, 282-7.

Collier, P. E., G. A. Liebler, S. B. Park, J. A. Burkholder, T. D. Maher and G. J. Magovern (1986). Is percutaneous insertion of the intra-aortic balloon pump through the femoral artery the safest technique? J Vasc Surg 3, 629-34.

Corral, C. H. and C. C. Vaughn (1986). Intraaortic balloon counterpulsation: an eleven-year review and analysis of determinants of survival. Tex Heart Inst J 13, 39-44.

Corwin, H. L., S. M. Sprague, G. A. DeLaria and M. J. Norusis (1989). Acute renal failure associated with cardiac operations. A case-control study. J Thorac Cardiovasc Surg 98, 1107-12.

Creswell, L. L., M. J. Moulton, J. L. Cox and M. Rosenbloom (1995). Revascularization after acute myocardial infarction. Ann Thorac Surg 60, 19-26.

Davies, A. R., R. Bellomo, J. S. Raman, G. A. Gutteridge and B. F. Buxton (2001). High lactate predicts the failure of intraaortic balloon pumping after cardiac surgery. Ann Thorac Surg 71, 1415-20.

Dietl, C. A., M. D. Berkheimer, E. L. Woods, C. L. Gilbert, W. F. Pharr and C. H. Benoit (1996). Efficacy and costeffectiveness of preoperative IABP in patients with ejection fraction of 0.25 or less. Ann Thorac Surg 62, 401-8; discussion $408-9$. 
Dormandy, J. A., R. H. Goetz and D. Kripke (1969). Hemodynamics and coronary blood flow with counterpulsation. Surgery 65, 31120 .

Elahi, M. M., G. K. Chetty, R. Kirke, T. Azeem, R. Hartshorne and T. J. Spyt (2005). Complications related to intra-aortic balloon pump in cardiac surgery: a decade later. Eur J Vasc Endovasc Surg 29, 591-4.

Gaudino, M., N. Luciani, S. Giungi, E. Caradonna, G. Nasso, R. Schiavello, G. Luciani and G. Possati (2005). Different profiles of patients who require dialysis after cardiac surgery. Ann Thorac Surg 79, 825-9; author reply 829-30.

Ghali, W. A., A. S. Ash, R. E. Hall and M. A. Moskowitz (1999). Variation in hospital rates of intraaortic balloon pump use in coronary artery bypass operations. Ann Thorac Surg 67, 441-5.

Ghosh, S., N. Roberts, R. K. Firmin, J. Jameson and T. J. Spyt (2002). Risk factors for intestinal ischaemia in cardiac surgical patients. Eur J Cardiothorac Surg 21, 411-6.

Gottlieb, S. O., J. A. Brinker, A. M. Borkon, C. H. Kallman, A. Potter, V. L. Gott and K. L. Baughman (1984). Identification of patients at high risk for complications of intraaortic balloon counterpulsation: a multivariate risk factor analysis. Am J Cardiol 53, 1135-9.

Gutfinger, D. E., R. A. Ott, M. Miller, A. Selvan, M. A. Codini, H. Alimadadian and T. M. Tanner (1999). Aggressive preoperative use of intraaortic balloon pump in elderly patients undergoing coronary artery bypass grafting. Ann Thorac Surg 67, 610-3.

Harken, D. E. (1958), presentation at the International College of Cardiology, Brussels, Belgium.

Harken, D. E. (1976). Counterpulsation. Med Instrum 10, 215.

Hauser, A. M., S. Gordon, V. Gangadharan, R. G. Ramos, D. C. Westveer, A. K. Garg and G. C. Timmis (1982). Percutaneous intraaortic balloon counterpulsation. Clinical effectiveness and hazards. Chest 82, 422-5.

Hausmann, H., E. V. Potapov, A. Koster, T. Krabatsch, J. Stein, R. Yeter, M. Kukucka, R. Sodian, H. Kuppe and R. Hetzer (2002). Prognosis after the implantation of an intra-aortic balloon pump in cardiac surgery calculated with a new score. Circulation 106, I203-6.

Hausmann, H., E. V. Potapov, A. Koster, H. Siniawski, M. Kukucka, M. Loebe, T. Krabatsch, R. Sodian, R. Yeter, H. Kuppe 
and R. Hetzer (2001). Predictors of survival 1 hour after implantation of an intra-aortic balloon pump in cardiac surgery. J Card Surg 16, 72-77; discussion 78 .

Hedenmark, J., H. Ahn, A. Henze, S. O. Nystrom, R. Svedjeholm and $\mathrm{H}$. Tyden (1989). Intra-aortic balloon counterpulsation with special reference to determinants of survival. Scand $J$ Thorac Cardiovasc Surg 23, 57-62.

Holman, W. L., Q. Li, C. I. Kiefe, D. C. McGiffin, E. D. Peterson, R. M. Allman, V. G. Nielsen and A. D. Pacifico (2000). Prophylactic value of preincision intra-aortic balloon pump: analysis of a statewide experience. J Thorac Cardiovasc Surg 120, 1112-9.

Ida, T., N. Yamate, S. Osaka, H. Takei, M. Ikeshita, T. Shoji, K. Tanaka and T. Takano (1984). Effects of intraaortic balloon pumping on acute myocardial infarction in 64 cases of cardiogenic shock, severe heart failure and mechanical heart failure. Jpn Circ J 48, 276-87.

Kahn, J. K., B. D. Rutherford, D. R. McConahay, W. L. Johnson, L. V. Giorgi and G. O. Hartzler (1990). Supported "high risk" coronary angioplasty using intraaortic balloon pump counterpulsation. J Am Coll Cardiol 15, 1151-5.

Kahn, J. K. (1991), IABP in the high risk coronary angioplasty patient, cardiac assists 6:1.

Kaleya, R. N. and S. J. Boley (1992). Acute mesenteric ischemia: an aggressive diagnostic and therapeutic approach. 1991 Roussel Lecture. Can J Surg 35, 613-23.

Kantrowitz, A., S. Tjonneland, P. S. Freed, S. J. Phillips, A. N. Butner and J. L. Sherman, Jr. (1968). Initial clinical experience with intraaortic balloon pumping in cardiogenic shock. Jama 203, 113-8.

Kantrowitz, A., T. Wasfie, P. S. Freed, M. Rubenfire, W. Wajszczuk and M. A. Schork (1986). Intraaortic balloon pumping 1967 through 1982: analysis of complications in 733 patients. Am J Cardiol 57, 976-83.

Khilji, S. A. and A. H. Khan (2004). Acute renal failure after cardiopulmonary bypass surgery. J Ayub Med Coll Abbottabad 16, $25-8$.

Klotz, S., T. Vestring, J. Rotker, C. Schmidt, H. H. Scheld and C. Schmid (2001). Diagnosis and treatment of nonocclusive mesenteric ischemia after open heart surgery. Ann Thorac Surg 72, 1583-6. 
Korfer, R., A. el-Banayosy, H. Posival, K. Minami, L. Kizner, L. Arusoglu and M. M. Korner (1996). Mechanical circulatory support with the Thoratec assist device in patients with postcardiotomy cardiogenic shock. Ann Thorac Surg 61, 314-6.

Kuki, S., K. Taniguchi, T. Masai, K. Yoshida, K. Yamamoto and H. Matsuda (2001). Usefulness of the low profile "True 8" intra-aortic balloon pumping catheter for preventing limb lschemia. Asaio J 47, 611-4.

Lazar, H. L., X. M. Yang, S. Rivers, P. Treanor, S. Bernard and R. J. Shemin (1992). Retroperfusion and balloon support to improve coronary revascularization. J Cardiovasc Surg (Torino) $33,538-44$.

Loebe, M., E. Hennig, J. Muller, S. Spiegelsberger, Y. Weng and R. Hetzer (1997). Long-term mechanical circulatory support as a bridge to transplantation, for recovery from cardiomyopathy, and for permanent replacement. Eur $J$ Cardiothorac Surg 11 Suppl, S18-24.

Loebe, M., J. Muller and R. Hetzer (1999). Ventricular assistance for recovery of cardiac failure. Curr Opin Cardiol $14,234-48$.

Mangi, A. A., E. R. Christison-Lagay, D. F. Torchiana, A. L. Warshaw and D. L. Berger (2005). Gastrointestinal complications in patients undergoing heart operation: an analysis of 8709 consecutive cardiac surgical patients. Ann Surg 241, 895-901; discussion 901-4.

McGee, M. G., S. L. Zillgitt, R. Trono, S. A. Turner, G. L. Davis, J. M. Fuqua, S. K. Edelman and J. C. Norman (1980). Retrospective analyses of the need for mechanical circulatory support (intrasortic balloon pump/abdominal left ventricular assist device or partial artificial heart) after cardiopulmonary bypass. A 44 month study of 14,168 patients. Am J Cardiol 46, 135-42.

Miller, J. S., T. F. Dodson, A. A. Salam and R. B. Smith, 3rd (1992). Vascular complications following intra-aortic balloon pump insertion. Am Surg 58, 232-8.

Moccetti, T., A. Riva, F. Clara, R. Tartini, U. Naegeli, C. Molo and L. Rondi (1982). [Clinical experiences with intraaortic balloon pumping]. Schweiz Med Wochenschr 112, 1286-9.

Moulopoulos, S. D., S. Topaz and W. J. Kolff (1962). Diastolic balloon pumping (with carbon dioxide) in the aorta--a mechanical assistance to the failing circulation. Am Heart $J$ $63,669-75$. 
Moulopoulos, S. D., S. R. Topaz and W. J. Kolff (1962). Extracorporeal assistance to the circulation and intraaortic balloon pumping. Trans Am Soc Artif Intern Organs 8, 85-9.

Nasu, M., M. Shinkai, H. Fujiwara, J. Sono, Y. Okada, S. Miyamoto, S. Nishiuchi, K. Tatemichi and T. Shomura (1991). Recovery of end-stage organ dysfunction by circulatory assist. ASAIO Trans 37, M345-7.

Naunheim, K. S., M. T. Swartz, D. G. Pennington, A. C. Fiore, L. R. McBride, P. S. Peigh, M. G. Barnett, K. J. Vaca, G. C. Kaiser and V. L. Willman (1992). Intraaortic balloon pumping in patients requiring cardiac operations. Risk analysis and longterm follow-up. J Thorac Cardiovasc Surg 104, 1654-60; discussion 1660-1.

Norman, J. C., D. A. Cooley, S. R. Igo, C. W. Hibbs, M. D. Johnson, J. G. Bennett, J. M. Fuqua, R. Trono and C. H. Edmonds (1977). Prognostic indices for survival during postcardiotomy intra-aortic balloon pumping. Methods of scoring and classification, with implications for left ventricular assist device utilization. J Thorac Cardiovasc Surg 74, 709-20.

Ota, T., M. Okada, Y. Tsuji, K. Ataka, K. Iwahashi and H. Matsuda (1992). Effect of intra-aortic balloon pumping after cardiac surgery: comparative study of use in coronary bypass and valve replacement. Kobe J Med Sci 38, 337-46.

Pfeiffer, S., P. Frisch, M. Weyand, S. M. Ensminger, R. Tandler, J. Sirch, T. Fischlein and R. Cesnjevar (2005). The use of preoperative intra-aortic balloon pump in open heart surgery. J Cardiovasc Surg (Torino) 46, 55-60.

Philips, P. A., A. T. Marty, A. M. Miyamoto and L. A. Brewer, 3rd (1975). A clinical method for detecting subendocardial ischemia after cardiopulmonary bypass. J Thorac Cardiovasc Surg $69,30-9$.

Pi, K., P. C. Block, M. G. Warner and E. B. Diethrich (1995). Major determinants of survival and nonsurvival of intraaortic balloon pumping. Am Heart J 130, 849-53.

Ramnarine, I. R., A. D. Grayson, W. C. Dihmis, N. K. Mediratta, B. M. Fabri and J. A. Chalmers (2005). Timing of intra-aortic balloon pump support and 1-year survival. Eur J Cardiothorac Surg 27, 887-92.

Scanlon, P. J., J. O'Connell, S. A. Johnson, J. M. Moran, R. Gunnar and R. Pifarrie (1976). Balloon counterpulsation following surgery for ischemic heart disease. Circulation 54, III $90-3$. 
Scholz, K. H., S. Ragab, F. von zur Muhlen, T. Schroder, G. S. Werner, L. Mindel and H. Kreuzer (1998). Complications of intra-aortic balloon counterpulsation. The role of catheter size and duration of support in a multivariate analysis of risk. Eur Heart J 19, 458-65.

Sommers, M. S., J. S. Stevenson, R. L. Hamlin, T. D. Ivey and A. C. Russell (1993). Mixed venous oxygen saturation and oxygen partial pressure as predictors of cardiac index after coronary artery bypass grafting. Heart Lung 22, 112-20.

Straub, U., J. Winning, P. Greilach, H. Isringhaus, G. Kalweit and $\mathrm{H}$. Huwer (2004). Alterations of mesenteric blood flow after cardiopulmonary bypass: a Doppler sonographic study. J Cardiothorac Vasc Anesth 18, 731-3.

Sturm, J. T., T. M. Fuhrman, S. R. Igo, D. A. Holub, M. G. McGee, J. M. Fuqua and J. C. Norman (1980). Quantitative indices of intra-aortic balloon pump (IABP) dependence during post-infarction cardiogenic shock. Artif Organs 4, 8-12.

Tatar, H., S. Cicek, U. Demirkilic, E. Ozal, H. Suer, M. Aslan and O. Y. Ozturk (1993). Vascular complications of intraaortic balloon pumping: unsheathed versus sheathed insertion. Ann Thorac Surg 55, 1518-21.

Torchiana, D. F., G. Hirsch, M. J. Buckley, C. Hahn, J. W. Allyn, C. W. Akins, J. F. Drake, J. B. Newell and W. G. Austen (1997). Intraaortic balloon pumping for cardiac support: trends in practice and outcome, 1968 to 1995. J Thorac Cardiovasc Surg 113, 758-64; discussion 764-9.

Venkateswaran, R. V., S. C. Charman, M. Goddard and S. R. Large (2002). Lethal mesenteric ischaemia after cardiopulmonary bypass: a common complication? Eur J Cardiothorac Surg 22, 5348 .

Vigneswaran, W. T., I. J. Reece and K. G. Davidson (1985). Intra-aortic balloon pumping: seven years' experience. Thorax $40,858-61$.

Warner, C. D., W. S. Weintraub, J. M. Craver, E. L. Jones, J. P. Gott and R. A. Guyton (1997). Effect of cardiac surgery patient characteristics on patient outcomes from 1981 through 1995. Circulation 96, 1575-9.

Zanardo, G., P. Michielon, A. Paccagnella, P. Rosi, M. Calo, V. Salandin, A. Da Ros, F. Michieletto and G. Simini (1994). Acute renal failure in the patient undergoing cardiac operation. Prevalence, mortality rate, and main risk factors. J Thorac Cardiovasc Surg 107, 1489-95. 


\section{Acknowledgments}

I would like to express my special gratitude to Professor R. Körfer for his support during the preparation of this work.

I would further like to express my deep gratitude to Dr. A. ElBanayosy for his continuous help and encouragement throughout the study.

My further thanks is due to Dr. A. Zittermann for his constant support, without whose help I would not have been able to prepare the statistics.

Also I'm very grateful to Dr. E. Murray and J. Catanese for their editorial advice. 


\title{
Curriculum Vitae
}

\section{Diyar Saeed}

\author{
Geboren im Irak, $\quad 05.08 .1977$ \\ Verheiratet \\ Einreise in die Bundesrepublik Deutschland \\ 18.04 .2001 \\ Schulausbildung \\ Grundschule und Gymnasium im Irak \\ $1982-1994$ \\ Hochschulausbildung \\ Studium der Humanmedizin an der Sulaimani Universität/Irak \\ $1994-2000$ \\ Berufserfahrungen \\ Arzt im Praktikum in der Inneren \\ $15.08 .2000-15.11 .2000$ \\ Abteilung/Irak \\ Arzt im Praktikum in der \\ $15.11 .2000-15.02 .2001$ \\ chirurgischen Abteilung \\ (Allgemeinchirurgie und Unfallchirurgie)/Irak
}

Assistenzarzt in der Abteilung

$24.06 .2002-01.06 .2003$

für Gefäß- und Thoraxchirurgie

im Kreiskrankenhaus Rendsburg

Assistenzarzt in der Klinik für

$01.06 .2003-01.08 .2006$

Herz- und Thoraxchirurgie des Herz-

und Diabeteszentrums Bad Oeynhausen,

Universitätsklinik der Ruhr Universität Bochum

Wissenschaftlicher Mitarbeiter in der Abteilung

Seit 01.08 .2006

für biomedizinische Technik,

Cleveland Clinic Foundation, Cleveland, USA

Ausführung der Gleichwertigkeitsprüfung(Köln)

19.05 .2004

Erteilung der Fachkunde Strahlenschutz

09.03 .2005

Erteilung der Fachkunde Rettungsmedizin

04.07 .2005

Erteilung der Fachkunde transesophageal Echocardiographie

29.01 .2006

Erteilung des Fortbildungszertifikats

08.06 .2006

der Ärztekammer Westfalen-Lippe

Cleveland, den 10.03.2007 